\title{
Design of hysteretic dampers with optimal ductility for the transverse seismic control of cable-stayed bridges
}

\author{
A. Camara ${ }^{1, *}$, R. Cristantielli ${ }^{2}$, M.A. Astiz ${ }^{3}$ and C. Málaga-Chuquitaype ${ }^{4}$ \\ ${ }^{1}$ Department of Civil Engineering. City, University of London, UK \\ ${ }^{2}$ Department of Civil Engineering, Environmental, Land, Construction and Chemistry. Politecnico di Bari, Italy \\ ${ }^{3}$ Department of Mechanics and Structures, School of Civil Engineering. Technical University of Madrid, Spain \\ ${ }^{4}$ Department of Civil and Environmental Engineering. Imperial College London, UK
}

\section{SUMMARY}

Cable-stayed bridges require a careful consideration of the lateral force exerted by the deck on the towers under strong earthquakes. This work explores the seismic response of cable-stayed bridges with yielding metallic dampers composed of triangular plates (TADAS) that connect the deck with the supports in the transverse direction. A design method based on an equivalent single-degree of freedom approximation is proposed. This is proved valid for conventional cable-stayed bridges with 200 and $400 \mathrm{~m}$ main spans, but not $600 \mathrm{~m}$. The height of the plates is chosen to (1) achieve a yielding capacity that limits the maximum force transmitted from the deck to the towers, and to (2) control the hysteretic energy that the dampers dissipate by defining their design ductility. In order to select the optimal ductility and the damper configuration, a multiobjective response factor that accounts for the energy dissipation, peak damper displacement and low-cycle fatigue is introduced. The design method is applied to cable-stayed bridges with different spans and decksupport connections. The results show that the dissipation by plastic deformation in the dampers prevents significant damage in the towers of the short-to-medium span bridges under the extreme seismic actions. However, the transverse response of the towers in the bridge with $600 \mathrm{~m}$ span is less sensitive to the TADAS dampers.

Copyright $\odot 2017$ John Wiley \& Sons, Ltd.

Received ..

KEY WORDS: cable-stayed bridges; seismic design; metallic dampers; energy balance; low-cycle fatigue

\section{INTRODUCTION}

1 The large retrofit costs of bridges and buildings after the Northridge and Kobe earthquakes in 2 the 90's unveiled the need for alternative design strategies that allow an improved control of 3 the structural performance. Supplemental Damping Systems (SDS) that concentrate the seismic 4 demand in auxiliary devices and reduce the damage in the main structural elements have been 5 successfully employed in buildings and bridges throughout the world [1]. The implementation of 6 SDS is particularly attractive in cable-stayed bridges because: (1) they can reduce the damage in 7 the towers, which play a fundamental role in the global resistance of the structure, (2) auxiliary 8 devices are easier to repair (if needed) than the large sections of the towers, leading to savings 9 in the associated retrofit and downtime costs, (3) the possible increment of displacements induced 10 by incorporating SDS can be easily accommodated by the large structural flexibility of cable-stayed

\footnotetext{
*Correspondence to: Department of Civil Engineering. City, University of London.

Northampton Square, London, UK. E-mail: alfredo.camara@ city.ac.uk 
Table I. Application of passive SDS to important cable-supported bridges in seismic areas.

\begin{tabular}{|c|c|c|c|}
\hline Bridge & Main span & SDS type & References \\
\hline SFOB (USA, 2013)* & $385 \mathrm{~m}$ & Transverse and longitudinal shear links (MD) & {$[5,6]$} \\
\hline Stonecutters (China, 2009) & $1018 \mathrm{~m}$ & Longitudinal Shock Transmission Units (VD) & \\
\hline Sutong (China, 2008) & $1088 \mathrm{~m}$ & Longitudinal VD & [7] \\
\hline Rion-Antirion (Greece, 2004) & $560 \mathrm{~m}$ & Transverse VD + fuse restrainers & {$[3,8]$} \\
\hline Bill Emerson (USA, 2003) & $351 \mathrm{~m}$ & Longitudinal Shock Transmission Units (VD) & [9] \\
\hline Tsurumi Fairway (Japan, 1994) & $510 \mathrm{~m}$ & Longitudinal Vane VD + anchor cables & [10] \\
\hline Yokohama Bay (Japan, 1989) & $460 \mathrm{~m}$ & Longitudinal Link Bearing Connections & [11] \\
\hline
\end{tabular}

bridges, and (4) these structures present inherently low damping values [2] and adding supplemental sources of energy dissipation is recommendable. Some of the most important cable-supported bridges recently constructed in seismic-prone areas include passive SDS, as summarised in Table I. The design of some of these important structures also makes allowance for structural damage in the towers under extreme earthquakes of very large return periods $\left(T_{R}\right)$, as is the case in the RionAntirion Bridge ( $T_{R}=2000$ years) [3] and the Stonecutters Bridge $\left(T_{R}=6000\right.$ years) [4]. SDS can be classified in terms of the mechanisms involved in the energy dissipation as: (1) rate-independent devices based on metal plasticity, e.g. yielding Metallic Dampers (MD), Friction Dampers (FD) and Lead Rubber Bearings (LRB), or (2) rate-dependent devices such as Viscous fluid Dampers (VD) and Visco-Elastic (VE) dampers.

The first numerical studies on SDS applied to cable-stayed bridges isolated the deck from the supports with LRB, observing that the efficiency of the SDS is reduced by increasing the main span length of the bridge [12]. Ali and Ghaffar [13] verified that distributing several LRB along the decktower connections, and not only at the towers, is more efficient in controlling the seismic forces and the displacements of the deck. Soneji and Jangid [14] combined transverse and longitudinal VD units with sliding and elastomeric bearings (including LRB) to isolate the deck in a two-dimensional numerical model of the Quincy Bay-view Bridge (USA, $274 \mathrm{~m}$ main span). It was observed that the damping added by the VD significantly reduced the response of the isolated bridge, avoiding possible impacts between the deck and the tower in the transverse direction and reducing the length of the expansion joints.

In addition to the numerical studies, it is essential to test the SDS experimentally before their implementation. El-Bahey and Bruneau $[15,16]$ conducted a detailed experimental and analytical programme on a bridge bent formed by two bi-steel columns connected by shear links and buckling restrained braces (MD) in the transverse direction. The laboratory test results demonstrated the increment of stiffness and strength of the bent with the incorporation of the SDS [15] and design expressions were proposed [16]. McDaniel et al. [5] conducted full-scale cyclic tests of the shear links employed in the San Francisco-Oakland Bay (SFOB) Bridge and observed their large overstrength. Later, these results were employed to define the nonlinear response of the links distributed along the tower height in a numerical model of the bridge, considering a cable-stayed solution and the self-anchored suspension bridge that was finally constructed [6]. It was found that the towers remained elastic in both configurations under the 1500- and 2500-year return period earthquakes owing to the dissipation of the shear links, particularly those at the tower midregion. More recently, Berman and Bruneau [17] tested large tubular shear links for application in bridge engineering and proposed design expressions for these devices.

The location and direction of the anti-seismic devices in the bridge is an important aspect in their design. Table I shows that most of the bridges include the SDS at the longitudinal deck-tower connection. Nevertheless, the significant damage in the tower of the Chi-Lu bridge (Taiwan, 2x120 m span) after the Chi-Chi earthquake (1999) can be attributed to the transverse seismic response of the bridge [18]. In effect, it is common practice to disconnect the deck from the towers in the longitudinal and vertical directions in order to minimise the seismic demand in the towers, but they 
are connected in the transverse direction to control the movement of the deck under service loads (e.g. wind actions) [19]. Unfortunately, few research works have focused on the control of cablestayed bridges in the transverse direction. Calvi et al. [20] proposed a conceptual design of VD in the deck-tower connection in order to control both the longitudinal and the transverse responses of the bridge. Camara and Astiz [21] conducted a numerical investigation on the seismic response of cablestayed bridges with VD and with the Triangular-plate Added Damping And Stiffness (TADAS) yielding MD proposed by Tsai et al. [22]. Although the efficiency of the TADAS devices in the protection of the towers was comparable to the VD, the dimensions of the triangular plates (width and height) were fixed and, thus, the dissipation capacity of the damper was not explored. Xing et al. [7] performed a sensitivity study on the influence of the yielding force of MD on the seismic response of the Sutong bridge (China). The optimum yielding force of the dampers was defined in that study as $38 \%$ of the one that would start damaging the towers of the bridge. However, important aspects like the risk of low-cycle fatigue in the dampers under strong seismic actions [23, 24] or the response of these devices under service loads were not discussed.

Research on the seismic response of cable-stayed bridges is clearly needed given the special social and economical importance of these structures within infrastructure networks. A survey carried out as part of this research revealed that in China $68 \%$ of the cable-stayed bridges have main spans below $500 \mathrm{~m}$, and the situation is similar in other countries. Moreover, it has been recently observed that strong deck-tower interactions in cable-stayed bridges with main spans between 200 and 500 $\mathrm{m}$ maximise their lateral response under transverse seismic actions [25], leading to potentially catastrophic results if the connections of the deck with the supports are not carefully designed. The aim of this paper is to propose a design methodology that results in TADAS dampers with optimal ductilities for the transverse seismic control of short-to-medium span cable-stayed bridges. The design method is based on an idealised Single-Degree-Of-Freedom (SDOF) response of the bridge in the transverse direction. The height of the triangular plates controls the damper's ductility demand whilst its yielding force is fixed and satisfies the minimum stiffness requirements under service loads. A multi-objective evaluation is conducted to find the optimal damper ductility from the results of nonlinear dynamic analyses, focusing on: (1) the reduction of the energy dissipated by plastic deformations in the main structure, (2) the relative deck-tower displacement and the risk of impacts, and (3) the low-cycle fatigue failure prevention. The design method is applied to three cable-stayed bridges with main span lengths of 200, 400 and $600 \mathrm{~m}$ and different deck-support connections. The results show that the TADAS devices reduce the damage and the level of cracking in the towers of the bridges with 200 and 400 m main spans, for which the assumptions made on the proposed design method are validated. However, it is observed that the TADAS dampers are not efficient in controlling the response of the largest bridge, with $600 \mathrm{~m}$ span.

\section{DESIGN OF TADAS DAMPERS WITH OPTIMAL DUCTILITY}

The proposed design procedure for the TADAS dampers in cable-stayed bridges, illustrated in Fig. 1, aims at protecting the towers whilst minimising the deformation in the deck during the earthquake. To this end, the elastic stiffness $\left(K_{d}\right)$ and yielding force $\left(R^{\max }\right)$ of the TADAS devices at the abutments (A1 and A2) and at the deck-tower connections (T1 and T2) are defined so that the deck moves uniformly in the transverse direction after the simultaneous yielding of the dampers. Consequently, the transverse response of the deck can be described as an equivalent SDOF system composed of a vibrating mass connected to the supports by a nonlinear spring that represents each TADAS device (with elastic stiffness $K_{d, i}$ and yielding force $R_{i}^{\max }$ for the damper at the $i$-th support) and by a linear spring that represents the stiffness of each support $\left(K_{s, i}\right)$, as it is shown in Fig. 1(b). The proposed design method is built upon the work of Priestley et al. [23], but introduces new features in order to control the damper ductility and to account for the particular response of cablestayed bridges. These innovative aspects are highlighted in Fig. 1(a) with shaded cells. The proposed methodology is valid for yielding MD other than TADAS devices by redefining the design of the damper in order to achieve the target capacity and stiffness (Step 6). 


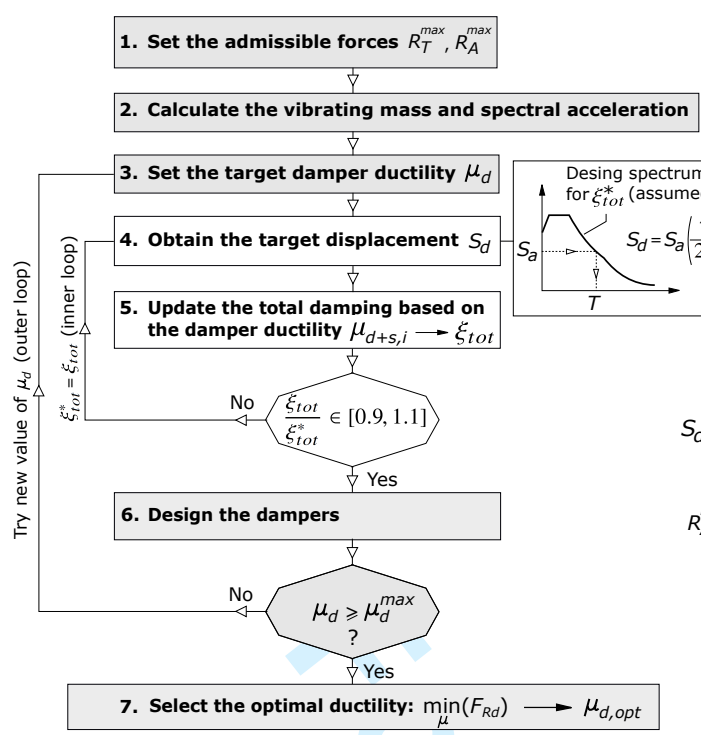

(a)

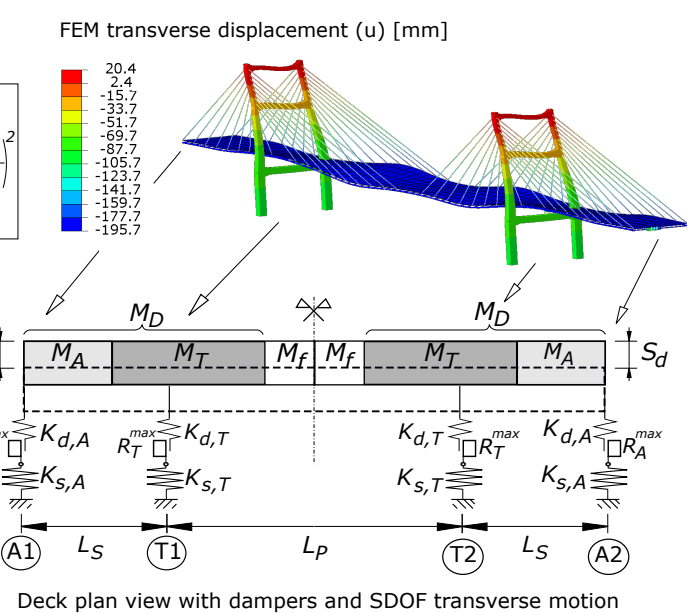

(b)

Figure 1. a) Damper design flowchart. b) Transverse displacement in one of the studied bridges $\left(L_{P}=200\right.$ $\mathrm{m}$, bridge with TADAS devices, Record $\# 1, t=5.57 \mathrm{~s}$ from the start of the earthquake, deformation $\times 80$ ) and equivalent SDOF model adopted in the proposed design.

\section{Step 1: Set the admissible forces}

First, the maximum forces transmitted from the deck to the $i$-th support are limited to $R_{i}^{\max }$ (where $i=T$ and $A$ refers to the dampers at the towers and the abutments, respectively). Consequently, $R_{T}^{\max }$ is the force for which the metallic dampers at the deck-tower connections yield in order to prevent damage of the towers. The maximum admissible force transmitted from the deck to the towers can be obtained from a nonlinear static (Pushover) analysis. In light of the significant postcracking stiffness degradation observed in the towers of short-span bridges (Section 5), the yield strength of the tower dampers is set to a fraction of the force required to initiate cracking as:

$$
R_{T}^{\max }=0.85 \cdot 0.9 \cdot R_{T}^{\text {crack }}=0.765 R_{T}^{\text {crack }}
$$

where $R_{T}^{\text {crack }}$ is the transverse reaction of the deck that induces cracking in the tower; the factor 0.9 accounts for a $10 \%$ damper over-strength; and 0.85 is a safety factor suggested by [23]. In order to favour a simultaneous yielding of all the dampers along the deck, the resistance of the TADAS devices at the abutments is limited to a force proportional to the yielding force of the dampers at the towers: $R_{A}^{\max }=k_{R} R_{T}^{\max }$. From purely static considerations this proportionality factor $\left(k_{R}\right)$ should be the ratio between the mass of the deck corresponding to the abutments and the towers. If the cross-section of the deck represented in Fig 1(b) is constant, the mass can be related to the length of the side span $\left(L_{S}\right)$ and the main span $\left(L_{P}\right)$ as: $k_{R}^{\text {static }}=L_{S} /\left(L_{P}+L_{S}\right)$. However, the characteristic dynamic interaction between the deck and the towers of cable-stayed bridges in the transverse direction needs to be considered in order to achieve a simultaneous yielding of the dampers along the deck. To this end, a Modal Response Spectrum Analysis (MRSA) on the Finite Element (FE) model of the bridge with the deck fully fixed to the supports can be conducted in order to estimate the peak transverse reactions of the deck at the abutments $\left(R_{A}^{\mathrm{MRSA}}\right)$ and at the towers $\left(R_{T}^{\mathrm{MRSA}}\right)$. The relationship between the yielding forces at these dampers is:

$$
R_{A}^{\max }=k_{R} R_{T}^{\max }=\frac{R_{A}^{\mathrm{MRSA}}}{R_{T}^{\mathrm{MRSA}}} R_{T}^{\max }
$$




\section{Step 2: Calculate the vibrating mass and the spectral acceleration}

The mass of the equivalent SDOF system associated with the lateral motion of the deck during the earthquake $\left(M_{D}\right)$ is a combination of the mass of the deck corresponding to the abutments and the towers: $M_{A}$ and $M_{T}$, respectively, as shown in Fig. 1(b). Note that $M_{D}$ refers to half of the deck in symmetric bridges. The side spans fully contribute to the mass affecting the TADAS dampers at the supports $\left(M_{D}\right)$. However, depending on the transverse flexibility of the deck, the towers and the cable-system, part of the mass of the deck at midspan $\left(M_{f}\right)$ moves in the transverse direction without affecting the TADAS devices. It is assumed that the relationship between the mass of the deck that corresponds to the dampers at the towers and that at the abutments is proportional to the deck reactions at these locations: $M_{T} / R_{T}^{\mathrm{MRSA}}=M_{A} / R_{A}^{\mathrm{MRSA}}$, and consequently:

$$
M_{D}=M_{A}+M_{T}=M_{A}\left(1+\frac{1}{k_{R}}\right)
$$

In the case of cable-stayed bridges in which the dynamic amplification due to the deck-tower interaction is not significant, the factor $k_{R}$ may be substituted by $k_{R}^{\text {static }}=L_{S} /\left(L_{P}+L_{S}\right)$ in expressions (2) and (3) in order to avoid the MRSA. This is relevant to the short-span bridge considered in this work, with $L_{P}=200 \mathrm{~m}$ (see Section 5). Finally, the maximum reaction in the equivalent SDOF system is known by assuming an elastic-perfectly plastic damper response, and the spectral acceleration is:

$$
S_{a}=\frac{R_{A}^{\max }+R_{T}^{\max }}{M_{D}}
$$

\section{Step 3: Set the target ductility of the dampers}

The ductility of the damper $\left(\mu_{d}\right)$ is selected in this step from a set of trial values (outer loop in Fig. 1(a)). As opposed to previous design approaches in which the plate dimensions are constrained based on certain 'workable' values that indirectly limit the ductility of the damper [7, 21], in this study $\mu_{d}$ is a design variable that will define the damper dimensions (Step 6).

\section{Step 4: Obtain the target displacement}

The vibration period $(T)$ of the equivalent SDOF system that governs the lateral motion of the deck is found by entering the design spectrum with the value of $S_{a}$ obtained from Eq. (4), as it is represented in Fig. 1(a) - Step 4. Initially, the system is assumed to be elastic and the spectrum is defined from the code specifications for a damping ratio: $\xi_{\text {tot }}^{*}=\xi_{e l}=0.05$, where the ${ }^{*}$ symbol denotes that the damping is assumed at this stage. Once the damping ratio and the target acceleration spectrum are known, the displacement demand of the equivalent SDOF system can be obtained as $S_{d}=S_{a}(T / 2 \pi)^{2}$. Subsequently, the effective ductility of the $i$-th damper is calculated next by accounting for the flexibility of the support in which it is located:

$$
\mu_{d+s, i}=\frac{\mu_{d} S_{d}}{S_{d}+u_{s, i}^{y}\left(\mu_{d}-1\right)}
$$

where $\mu_{d+s, i}$ is the effective ductility of the system composed by the $i$-th damper associated in series with the corresponding support (see Fig. 1(b)), $i=A$ refers to the TADAS dampers at the abutments and $i=T$ to those at the towers; $u_{s, i}^{y}=R_{i}^{\max } / k_{s, i}$ is the elastic displacement of the support to which the TADAS device is connected at the instant when yielding in the damper occurs; and $k_{s, i}$ is the transverse stiffness of the $i$-th support. The lateral displacement of the tower at the level of the lower strut due to the force introduced by the deck reduces the efficiency of the dampers in dissipating the seismic energy at these locations. This is not the case at the abutments, which are considered fully rigid in the transverse direction and therefore $u_{s, A}^{y}=0$ and $\mu_{d+s, A}=\mu_{d}$ in Eq. (5). 


\section{Step 5: Update the total damping}

The damping factor corresponding to the $i$-th support depends on its effective ductility. For elasticperfectly plastic systems [26]:

$$
\xi_{d+s, i}=\xi_{e l}+C_{e p}\left(\frac{\mu_{d+s, i}-1}{\pi \mu_{d+s, i}}\right)
$$

where $\xi_{e l}=0.05$ is the damping ratio of the structure in the elastic range; $C_{e p}=0.85$ if $T>1 \mathrm{~s}$, which is usually the case in cable-stayed bridges given their large flexibility.

The total damping of the equivalent SDOF system results from a weighted average that includes the vibrating mass associated with each support:

$$
\xi_{\text {tot }}=\frac{\xi_{d+s, A} M_{A}+\xi_{d+s, T} M_{T}}{M_{D}}
$$

If the difference between the assumed damping ratio $\left(\xi_{\text {tot }}^{*}\right)$ and the calculated one $\left(\xi_{\text {tot }}\right)$ is larger than a certain tolerance that is set as $10 \%$ in this work, Steps 4-5 are repeated (inner loop in Fig. 1(a)) by considering $\xi_{\text {tot }}^{*}=\xi_{\text {tot }}$. The procedure converges rapidly and the tolerance criterion is usually satisfied in 2 or 3 iterations. At this point the design elastic stiffness in each damper is obtained as:

$$
K_{d, i}=\frac{\mu_{d} R_{i}^{\max }}{S_{d}-u_{s, i}^{y}}
$$

\section{Step 6: Design of the dampers}

The dampers are designed to achieve the target ductility and yielding force. The height of the triangular plates in the $i$-th damper $\left(H_{p, i}\right)$ is defined in terms of the required ductility $\left(\mu_{d}\right)$, which is related to its elastic stiffness $\left(K_{d, i}\right)$ in Eq. (8). The plates are fixed at the base and free at the top, where they receive the lateral load from the deck. This configuration, in addition to the triangular shape of the plates, provides a constant distribution of curvature along their height. From the analysis of a cantilever with a point load at the free end, the height of the plate is defined as:

$$
H_{p, i}=\sqrt{\frac{2 R_{i}^{\text {max }} E_{s} t_{p}}{3 f_{s y} K_{d, i}}}
$$

where $f_{s y}$ and $E_{s}$ are the yielding stress and the elastic modulus of the steel, respectively; $t_{p}$ is the thickness of the plates. The width and (especially) the height of the dampers may be limited for constructive reasons and such constraints can be introduced at this step.

The number of plates in each damper is defined so that it yields at the required limit force:

$$
N_{d, i}=\frac{4 R_{i}^{\max } H_{p, i}}{f_{s y} t_{p}^{2} B_{p}}
$$

$B_{p}$ being the width of the triangular plates. Finally, the length of the damper (for a single-row plate arrangement) is:

$$
L_{d, i}=t_{p}\left(2 N_{d, i}-1\right)
$$

which is constrained by the width of the deck $(B)$.

\section{Step 7: Selection of the optimal ductility}

Following the damper design of the previous step, a series of nonlinear response history analyses (NL-RHA) is conducted on the bridges with the range of ductility demands proposed above. The optimal damper configuration is selected by comparing the NL-RHA results. Large values of the ductility factor $\left(\mu_{d}\right)$ selected by the designer in Step 3 lead to large dissipation levels of the seismic energy but also to a higher risk of low-cycle fatigue. A performance factor $\left(F_{R d}\right)$ based on the 
energy dissipation at the towers, the displacement of the dampers and their low-cycle fatigue risk is proposed to find the optimum TADAS devices:

$$
F_{R d}=\frac{W_{\Omega} \frac{\Omega}{\Omega_{a d m}}+W_{u} \frac{u_{d T}^{\max }}{u_{d T, a d m}^{\max }}+\sum_{i} W_{\mathrm{PM}, i} \mathrm{PM}_{i}}{W_{\Omega}+W_{u}+\sum_{i} W_{\mathrm{PM}, i}}
$$

where $W_{\Omega}, W_{u}$ and $W_{\mathrm{PM}, i}$ are weightings related to the fraction of the input seismic energy that is dissipated by plastic deformations in the towers ( $\Omega$ factor, Section 6.1 ), the peak relative displacement of the dampers at the towers $\left(u_{d T}^{\max }\right.$, Section 6.3) and the low-cycle fatigue factor at the $i$-th damper ( $\mathrm{PM}_{i}$, Section 6.4), respectively. The proposed weightings may be calibrated to give more importance to specific response measurements or to the dampers at particular supports. In this study, all the weightings are considered equal to one. The sub-index ' $a d m$ ' refers to the maximum value of the response measurement that is admissible considering the project requirements and constraints. Note that the damper displacement is limited at the towers but not at the abutments since there are usually less space constraints to the lateral movement of the deck at these locations. After the performance factor $F_{R d}$ is obtained for the whole range of trial damper ductilities, the optimal value of ductility $\left(\mu_{d, o p t}\right)$ is selected as the one for which $F_{R d}$ is minimised.

\section{PROPOSED BRIDGES AND NUMERICAL MODELS}

In order to illustrate the proposed design method and to study the response of cable-stayed bridges with a conventional range of main span lengths $\left(L_{P}\right)$, three cable-stayed bridges with $L_{P}=200$, 400 and $600 \mathrm{~m}$ are considered in this work. Each bridge has two H-shaped reinforced concrete towers with three transverse struts. Fig. 2 shows the elevation and plan view of the deck, the towers and the cable-system. Different FE models are defined parametrically in terms of $L_{P}$ according to [27]. The tower geometry includes a smooth transition between the lateral legs and the transverse struts, as shown in Fig. 2(b). The thickness of the tower cross-sections $\left(t_{c}\right)$ is selected so that: (1) the maximum normal stress under the self-weight and the live load is below $10 \mathrm{MPa}$, and (2) the maximum width-to-thickness ratio is limited to avoid instability problems as $t_{c} /\left(d_{l}-2 t_{c}\right) \geq 1 / 10$ [28], where $H$ is the tower height above the deck and $d_{l}=H / 13$ is the size of the hollow square cross-section of the tower between the base and the lower strut (Fig. 2(b)). The concrete thickness $t_{c}$ in the towers is uniformly distributed along their height and the transverse struts.

The reinforcement is defined to provide the tower sections with sufficient confinement and rotation capacity according to [29]. The ratio between the longitudinal and transverse steel reinforcement with respect to the gross concrete area at the tower base is 2.4 and $0.8 \%$, respectively. The same reinforcement ratios are considered in all models. The details of the reinforcement in the inner and outer perimeters are given in Fig. 2(b).

The FE model of the bridge accounts for the possible damage in the towers and the consequent loss of efficiency of the dampers. A confined concrete model with a characteristic strength $\left(f_{c k}\right)$ of $40 \mathrm{MPa}$ is considered in the towers, with elastic modulus of $E_{c}=35 \mathrm{GPa}$. The model of the concrete includes softening when the normal compressive strain exceeds $\varepsilon_{c s}=-0.13 \%$. The model of Mazars and Pijaudier-Cabot [30] is employed to represent the concrete cracking in the towers. The stress and strain corresponding to crack initiation are $f_{c, \text { crack }}=3.5 \mathrm{MPa}$ and $\varepsilon_{c, \text { crack }}=0.01 \%$, respectively, whereas the strength of the concrete is considered null beyond $\varepsilon=0.035 \%$. The model of the reinforcement in the towers is bilinear, with elastic modulus of $E_{s}=210 \mathrm{GPa}$. The reinforcement steel is set to capture yielding when the strain reaches $\varepsilon_{s y}=0.26 \%\left(f_{s y}=552 \mathrm{MPa}\right)$ and failure at $\varepsilon_{s u}=11.4 \%\left(f_{s u}=665 \mathrm{MPa}\right)$.

The towers are defined in the FE model by means of 'fiber-section' beam elements that account for the influence of the variable seismic axial load on the flexural response of the towers [31]. Prior sensitivity studies carried out as part of this research have confirmed the adequacy of defining the element length in the towers as half of the plastic hinge length proposed for concrete piers by Priestley et al. [23], using linear-interpolation beam elements. The resulting element lengths in the 
(a) Elevation (half bridge, symmetric):

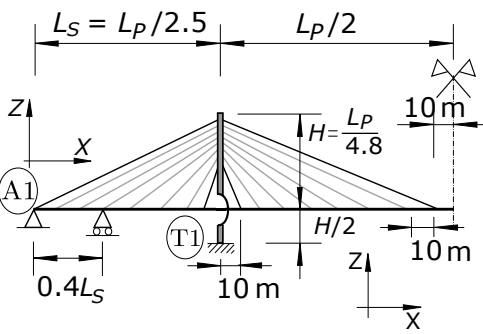

(b) H-shaped towers:

(c) Plan view of the 'stiff' connection (half-deck):
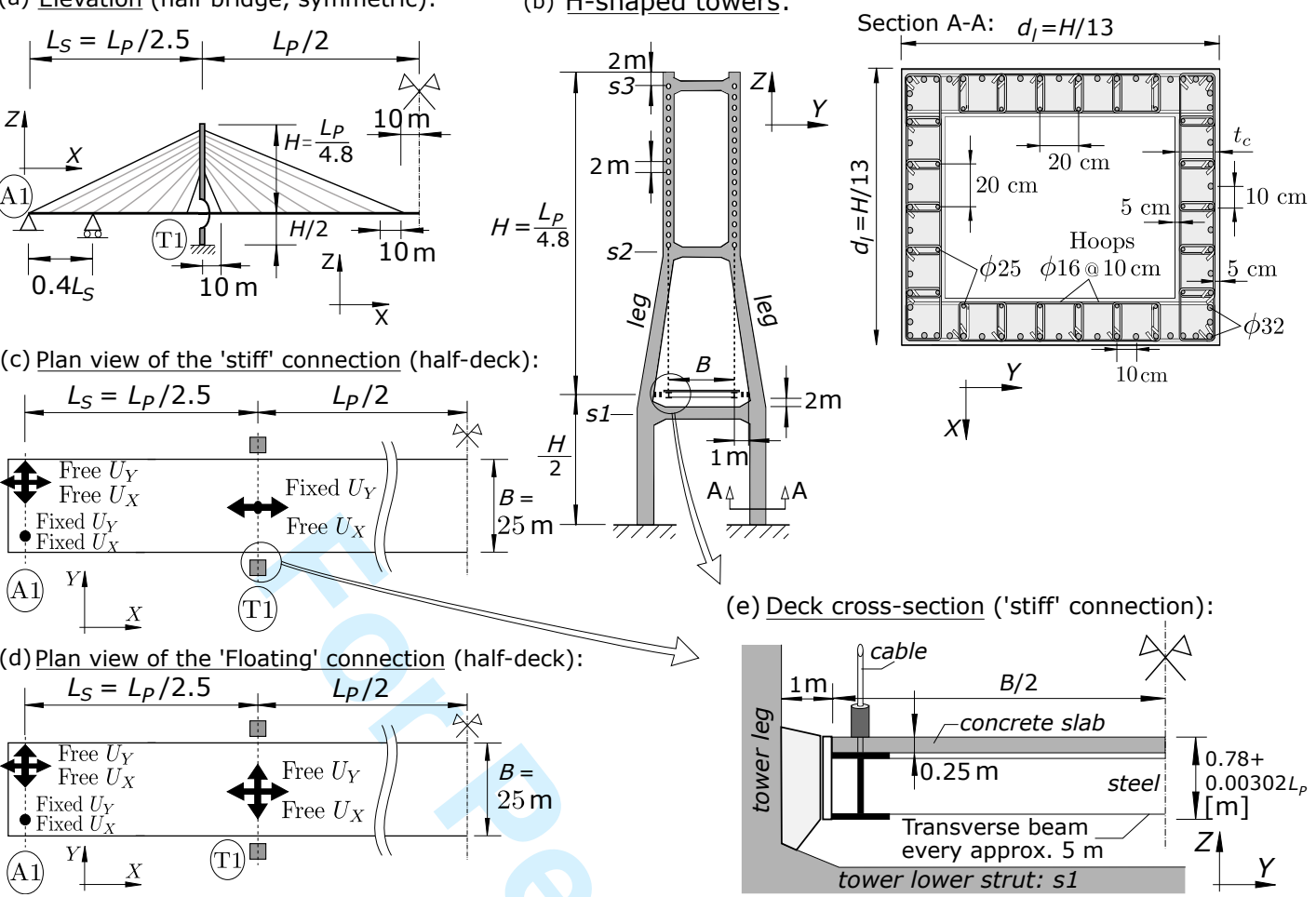

Figure 2. Schematic bridge elevation and plan view of the supports. Model without dampers.

lateral legs of the towers are $0.71,1.21$ and $1.71 \mathrm{~m}$ in the 200,400 and $600 \mathrm{~m}$ main span bridges, respectively. In the transverse struts of the towers the element length is approximately $0.71 \mathrm{~m}$, regardless of the span. Geometric nonlinearities ( $P-\Delta$ effects) are included in all the analyses.

The deck cross-section is composed of two longitudinal steel I-shaped girders at the edges, connected by a concrete slab and transverse beams at approximately $5 \mathrm{~m}$ intervals (Fig. 2(e)). The FE model of the deck is defined with linear-interpolation beam elements at the centroids of the steel girders that are rigidly connected to shell elements located on the mid-plane of the deck slab to represent the effect of the concrete in the composite section. The materials in the deck remain elastic during the analysis and their elastic moduli are the same as those described for the tower.

The intermediate piers located at the side spans between the towers and the abutments (Fig. 2(a)) exclusively constrain the vertical movement of the deck, releasing its longitudinal and transverse displacements in all cases. The connection between the deck and the towers is free in the longitudinal $(X)$ and vertical $(Z)$ directions. The transverse $(Y)$ deck-tower connection depends on the case under consideration, as it is illustrated in Fig. 3: (a) in the bridge with fully-rigid connection (referred to as 'stiff' connection), which is a conventional solution in the design of cable-stayed bridges in seismic areas, a rigid element links the deck and the towers preventing relative movements between them in the transverse direction (Fig. 3(a)); (b) in the structures with free deck-tower connection (referred to as 'floating' connection) the deck is released from the towers in all directions (Fig. 3(b)); (c) in the solution with the TADAS devices (referred to as TADAS connection) the deck is exclusively connected to the towers in the transverse direction by means of these dampers (Fig. $3(\mathrm{c})$ ). The triangular plates in the TADAS devices are made of structural steel with $f_{s y}=500 \mathrm{MPa}$ and $E_{s}=210 \mathrm{GPa}$. The slotted connection between the top of the plate and the transverse beam of the deck allows for free vertical $(Z)$ and longitudinal $(X)$ movements, making the damper active only in the transverse direction $(Y)$, as it is represented in Fig. 3(d). Note that the floating deck-tower connection is not normally feasible in practice due to the excessive lateral displacement of the deck under service loads and it is considered here for purposes of comparison only. The connection of the deck with the towers in the dynamic analysis (NL-RHA) of the structures with the TADAS dampers 
Table II. PEER-NGA ground motions. 'ID' record sequence number; $M_{w}$ moment magnitude; $R_{\text {epi }}$ epicentral distance; $V_{s, 30}$ average shear-wave velocity over the uppermost $30 \mathrm{~m} ; D_{0-100 \%}$ original record duration; $D_{0-95 \%}$ strong-shaking interval; SF scale factor.

\begin{tabular}{lccccccc}
\hline Earthquake, year & $\mathrm{ID}$ & $M_{w}$ & $R_{\mathrm{epi}}[\mathrm{km}]$ & $V_{s, 30}[\mathrm{~m} / \mathrm{s}]$ & $D_{0-100 \%}[\mathrm{~s}]$ & $D_{0-95 \%}[\mathrm{~s}]$ & $\mathrm{SF}$ \\
\hline Imperial Valley, 1973 & 1 & 6.5 & 13.5 & 259.9 & 56.95 & 30.74 & 10.0 \\
Morgan Hill, 1984 & 2 & 6.1 & 26.4 & 215.5 & 39.96 & 26.64 & 8.56 \\
Landers, 1992 & 3 & 7.3 & 121.8 & 367.5 & 43.82 & 31.42 & 9.46 \\
Landers, 1992 & 4 & 7.3 & 11.03 & 379.3 & 43.82 & 32.20 & 7.69 \\
Big Bear, 1992 & 5 & 6.5 & 77.3 & 282.1 & 59.91 & 37.89 & 10.0 \\
Big Bear, 1992 & 6 & 6.5 & 33.5 & 325.8 & 46.63 & 30.45 & 7.69 \\
Big Bear, 1992 & 7 & 6.5 & 35.0 & 297.0 & 99.91 & 32.97 & 7.50 \\
Manjil, 1990 & 8 & 7.4 & 50.0 & 302.6 & 60.35 & 30.19 & 5.92 \\
Manjil, 1990 & 9 & 7.4 & 93.3 & 289.7 & 35.35 & 29.99 & 4.97 \\
Hector Mine, 1999 & 10 & 7.1 & 61.2 & 370.1 & 59.82 & 29.78 & 7.69 \\
Darfield, 2010 & 11 & 7.0 & 43.6 & 638.4 & 139.95 & 36.02 & 7.52 \\
Darfield, 2010 & 12 & 7.0 & 9.4 & 295.7 & 59.56 & 38.81 & 5.56 \\
Arithmetic mean & & & & $\mathbf{3 3 5 . 3}$ & $\mathbf{6 2 . 1 7}$ & $\mathbf{3 2 . 2 6}$ & $\mathbf{7 . 7 1}$ \\
\hline
\end{tabular}

is modelled with a single transverse truss element in which the mass of the MD is lumped at the nodes. The nonlinear response of the dampers is simulated by means of an equivalent elastoplastic material with a linear kinematic hardening rule that captures the Bauschinger effect. This model is suited to study the global response of metals under cyclic loading conditions [32]. Increased values of the material hardening have been employed in previous studies on structures with yielding MD to represent unintentional increments in the plate thickness, the material over-strength and membrane effects of the steel plates at large displacements [33]. In this work, an elastoplastic hardening stiffness of $8 \%$ the elastic stiffness in the TADAS devices is assumed in the NL-RHA in line with the experimental results reported in [22].

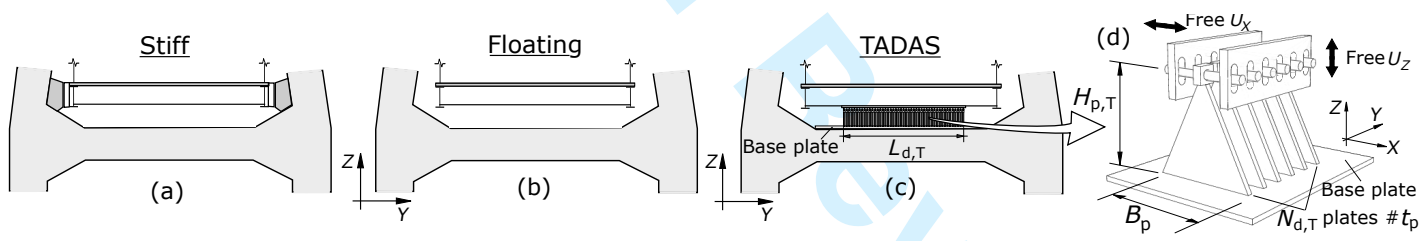

Figure 3. Deck-tower connection in the three cases considered: (a) fully-rigid ('stiff') connection, (b) floating connection, (c) TADAS connection, (d) detail of the TADAS connection.

A semi-harp cable-system arrangement is considered in this work (Fig. 2(a)). Each cable is defined in the FE models by means of a single 'truss' element (elastic modulus $E_{p}=195 \mathrm{GPa}$ ), thus ignoring the cable-structure interaction during the earthquake. The connection of the cables at the towers and at the deck is solved by means of rigid links with lumped masses that simulate the effect of the cable anchorages. The flexibility of the tower foundation is described by means of translational springs of constant stiffnesses in the $X, Y$ and $Z$ directions and fully restrained rotation.

\section{SEISMIC ACTION}

A total of twelve natural accelerograms selected from the PEER-NGA database [34] are considered in this study and presented in Table II. These are selected to fit the horizontal design spectrum given by EN1998-1 [35] for soft soil conditions (type D), moment magnitudes above 5.5 (Type 1 spectrum), and a Peak Ground Acceleration of $0.67 \mathrm{~g}$. In order to keep the implications of the results general, no attempt has been made to relate the proposed design spectrum to any particular location. However, this level of demand is broadly consistent with the extreme 2500-year return period event considered in the design of the San Francisco-Oakland Bay (SFOB) bridge [6], both in terms of spectral accelerations and displacements, as shown in Figure 4. 

variability effects. bridges, respectively.

The scale factors (SF) included in Table II affect the amplitudes of the original accelerograms, not their frequency content. The scaled average acceleration spectrum is above $90 \%$ and below $130 \%$ of the target design spectrum in the relevant period range [0.029;7] s. This range is selected after a modal analysis conducted in all the FE models, covering possible period elongations and the contribution of high-order modes (up to $35 \mathrm{~Hz}$ ). SF ranging from 4.97 up to 10 were employed, the level of which has been found not to introduce any significant bias by other studies [36].

The NL-RHA analyses in this work only cover the window of strong ground shaking $D_{0-95 \%}$ due to the large number of computationally expensive dynamic analyses that are conducted. Table II shows the important reduction in the analysis duration when comparing the reduced time-window $\left(D_{0-95 \%}\right)$ with the complete one given by the ground motion database $\left(D_{0-100 \%}\right)$. The accelerograms are applied synchronously to the bridge supports only in the transverse direction $(Y)$, ignoring spatial

\section{APPLICATION OF THE PROPOSED DESIGN METHOD}

The methodology presented in Section 2 is applied here to design the TADAS devices in the proposed bridges under the demands described previously. According to Step 1, the admissible damper forces are selected from the Pushover analysis of the towers. A point load is applied at the deck-tower connection and it is gradually increased to simulate the effect of the lateral reaction of the deck on the towers $\left(R_{T}\right)$. The load of the deck is equally distributed to the two connections between the lower strut and the legs in order to avoid introducing tensile axial loads in the concrete. Fig. 5 presents the transverse displacement of the lower strut versus the applied load. The points on the load-displacement curve that are associated with key behavioural stages (i.e. the first crack in the concrete and the first yielding in the reinforcement) are also included in this figure. The point $\left(u_{T}^{\text {crack }}, R_{T}^{\text {crack }}\right)$ marks the initial cracking of the concrete at the lower strut (section B in Fig. 5), and the point $\left(u_{T}^{\text {yield }}, R_{T}^{\text {yield }}\right.$ ) represents the first reinforcement bar yielding at the tower base (section A in Fig. 5). A significant degradation of the stiffness is observed after cracking in Fig. 5, especially in the bridge with the shortest main span. This highlights the importance of the damper yielding before cracking in the tower occurs (Eq. (1)). Consequently, the capacities of the TADAS devices were set to: $R_{T}^{\max }=0.765 R_{T}^{\text {crack }}=8.40,22.59$ and $39.01 \mathrm{MN}$ in the 200, 400 and $600 \mathrm{~m}$ span

The yielding force of the TADAS devices at the abutments is defined by means of the proportionality factor $k_{R}=R_{A}^{\mathrm{MRSA}} / R_{T}^{\mathrm{MRSA}}$ resulting from the MRSA of the bridge. These ratios are 


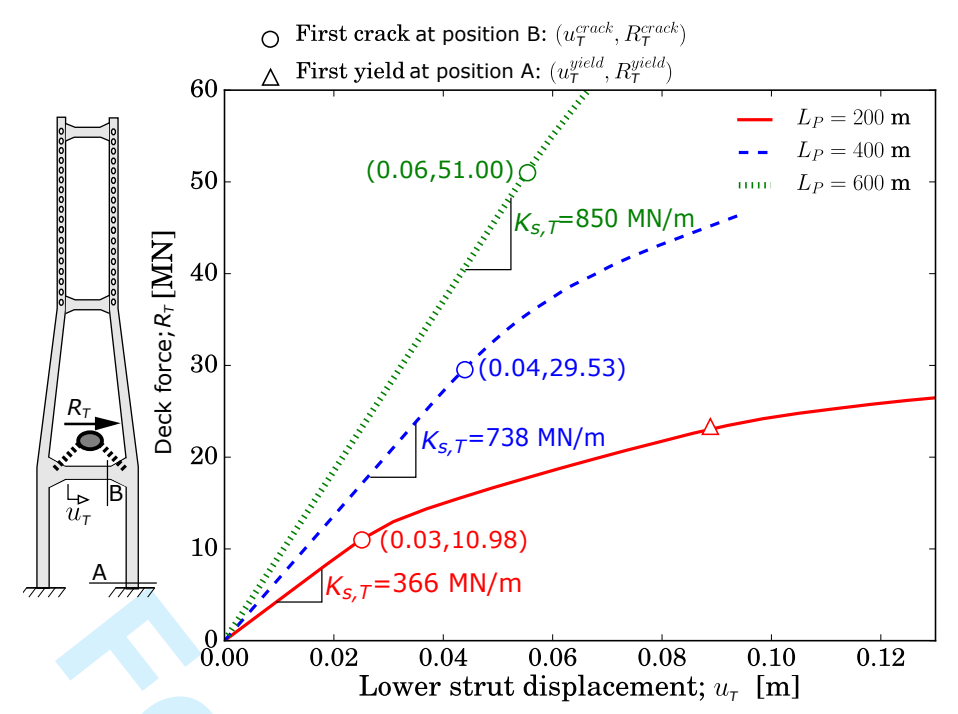

Figure 5. Pushover curves describing the response of the tower in the transverse direction.

$k_{R}=0.30,0.53$ and 0.46 for the proposed models with 200, 400 and $600 \mathrm{~m}$ main span, respectively. Note that from a purely static consideration this ratio is $k_{R}^{\text {static }}=0.29$ in the studied bridges, regardless of the main span, because the length of the deck adjacent to the abutments is $29 \%$ of the length adjacent to the towers, as shown in Figs. 2(c) and (d). In the $200 \mathrm{~m}$ span bridge the MRSA can be omitted by adopting $k_{R} \approx k_{R}^{\text {static }}=0.29$. However, the values of $k_{R}$ obtained with the MRSA show that for larger bridges the length of the deck affecting the towers during the ground shaking is not directly proportional to the length of the adjacent spans. This is attributed to the large transverse flexibility of the deck in long-span bridges.

In Step 2, the vibrating mass of the deck that contributes to the response of the TADAS devices at the abutments is defined by considering that the dampers at these locations resist the inertia forces associated with half of the weight of the side spans of the bridge: $M_{A}=0.5 q_{d} B L_{S} / g$, where $q_{d}=10.29 \mathrm{kN} / \mathrm{m}^{2}$ is the weight per unit area of the deck (including the structural and non-structural mass), $B=25 \mathrm{~m}$ is the deck width and $g=9.81 \mathrm{~m} / \mathrm{s}^{2}$ is the gravitational acceleration. From the value of $M_{A}$, the mass of the deck corresponding to the dampers at the towers $\left(M_{T}\right)$ is obtained in Eq. (3). Note that these masses refer to half of the deck as shown in Fig. 1(b)

In Step 3, the design ductility demand in the TADAS dampers of the towers and the abutments is selected from the range of values: $\mu_{d}=[1,2,3,4,5,6,8]$. After defining the damper ductility and target displacement $\left(S_{d}\right)$ in Step 4, their stiffness is obtained in Step 5 by accounting for the flexibility of the towers. The elastic stiffnesses of the towers are calculated from the loaddisplacement response in Fig. 5: $k_{s, T}=R_{T}^{\text {crack }} / u_{T}^{\text {crack }}=366,738$ and $850 \mathrm{MN} / \mathrm{m}$ for the 200, 400 and $600 \mathrm{~m}$ span bridges, respectively. The displacements of the lower strut of the tower when the TADAS devices yield are obtained as: $u_{s, T}^{y}=R_{T}^{\max } / k_{s, T}=0.023,0.031$ and $0.046 \mathrm{~m}$, respectively.

The thickness of the metallic plates is considered as $t_{p}=20 \mathrm{~mm}$ in the design of the dampers in Step 6. The height of the plates $\left(H_{p, i}\right)$ is obtained from Eq. (9) and it is included in Table III, along with other characteristic features of the dampers for bridges with different main spans. Considering the same bridge, the stiffness of the dampers increases by increasing the design ductility, and the height of the plates is reduced accordingly because the width of the plates $\left(B_{p}\right)$ is kept constant. The maximum height of the plates is set as $2.0 \mathrm{~m}$, which is the distance between the deck and the lower strut in Fig. 2(b). This limit is not exceeded in the proposed dampers, as it can be observed from Table III. In the present study, the width of the plates $\left(B_{p}\right)$ is the same in the dampers along the deck and it is not constrained as there is sufficient space in the abutments and the transverse struts of the towers in the longitudinal direction. However, $B_{p}$ has been increased with the main span of the bridge in order to reduce the number of plates in the TADAS dampers $\left(N_{d, i}\right)$ and their length $\left(L_{d, i}\right)$. 
Table III. Mechanical properties and dimensions of the TADAS devices. Symbols and units: $L_{P}$ main span length $[\mathrm{m}] ; \mu_{d}$ damper's design ductility; $F_{R d}$ damper performance factor from Eq. (12); $T$ vibration period (SDOF) $[\mathrm{s}] ; \xi_{\text {tot }}$ damping ratio (SDOF); $B_{p}$ plate width $[\mathrm{m}] ; K_{d, i}$ elastic stiffness of the $i$-th damper $[\mathrm{MN} / \mathrm{m}]$; $H_{p, i}$ plate height of the $i$-th damper [m]; $N_{d, i}$ number of plates in the $i$-th damper; $L_{d, i}$ length of the $i$-th damper $[\mathrm{m}]$. The values corresponding to the optimal ductility $\mu_{d, o p t}$ (minimum $F_{R d}$ ) are highlighted.

\begin{tabular}{cccccccccccccc}
\hline & & & & & \multicolumn{4}{c}{ Abutment connection } & \multicolumn{5}{c}{ Tower connection } \\
\cline { 8 - 13 }$L_{P}$ & $\mu_{d}$ & $F_{R d}$ & $T$ & $\xi_{\text {tot }}$ & $B_{p}$ & $K_{d, A}$ & $H_{p, A}$ & $N_{d, A}$ & $L_{d, A}$ & $K_{d, T}$ & $H_{p, T}$ & $N_{d, T}$ & $L_{d, T}$ \\
\hline 200 & 1.0 & 0.37 & 3.3 & 0.05 & 0.6 & 3.7 & 1.84 & 140 & 5.58 & 12.9 & 1.82 & 461 & 18.42 \\
& 2.0 & 0.26 & 2.7 & 0.18 & 0.6 & 11.4 & 1.06 & 80 & 3.18 & 39.9 & 1.03 & 262 & 10.46 \\
& 3.0 & 0.25 & 2.6 & 0.23 & 0.6 & 18.7 & 0.82 & 62 & 2.46 & 65.7 & 0.80 & 204 & 8.14 \\
& 4.0 & 0.23 & 2.5 & 0.25 & 0.6 & 26.1 & 0.70 & 53 & 2.10 & 91.6 & 0.68 & 172 & 6.86 \\
& $\mathbf{5 . 0}$ & $\mathbf{0 . 2 2}$ & $\mathbf{2 . 5}$ & $\mathbf{0 . 2 7}$ & $\mathbf{0 . 6}$ & $\mathbf{3 3 . 4}$ & $\mathbf{0 . 6 2}$ & $\mathbf{4 6}$ & $\mathbf{1 . 8 2}$ & $\mathbf{1 1 7 . 6}$ & $\mathbf{0 . 6 0}$ & $\mathbf{1 5 2}$ & $\mathbf{6 . 0 6}$ \\
& 6.0 & 0.25 & 2.5 & 0.28 & 0.6 & 40.9 & 0.56 & 42 & 1.66 & 143.9 & 0.54 & 137 & 5.46 \\
& 8.0 & 0.31 & 2.4 & 0.30 & 0.6 & 55.9 & 0.48 & 36 & 1.42 & 197.2 & 0.46 & 117 & 4.66 \\
\hline 400 & 1.0 & 0.31 & 2.2 & 0.05 & 1.2 & 17.8 & 1.84 & 332 & 13.26 & 35.4 & 1.80 & 613 & 24.50 \\
& $\mathbf{2 . 0}$ & $\mathbf{0 . 1 9}$ & $\mathbf{1 . 5}$ & $\mathbf{0 . 1 8}$ & $\mathbf{0 . 8}$ & $\mathbf{7 0 . 9}$ & $\mathbf{0 . 9 3}$ & $\mathbf{2 5 0}$ & $\mathbf{9 . 9 8}$ & $\mathbf{1 4 8 . 7}$ & $\mathbf{0 . 8 8}$ & $\mathbf{4 4 9}$ & $\mathbf{1 7 . 9 4}$ \\
& 3.0 & 0.22 & 1.4 & 0.23 & 0.8 & 129.3 & 0.68 & 185 & 7.38 & 278.1 & 0.64 & 328 & 13.10 \\
& 4.0 & 0.29 & 1.3 & 0.26 & 0.8 & 192.2 & 0.56 & 152 & 6.06 & 420.0 & 0.52 & 267 & 10.66 \\
& 5.0 & 0.42 & 1.3 & 0.29 & 0.8 & 260.2 & 0.48 & 130 & 5.18 & 576.0 & 0.45 & 228 & 9.10 \\
& 6.0 & 0.51 & 1.2 & 0.31 & 0.8 & 334.3 & 0.43 & 115 & 4.58 & 749.3 & 0.39 & 200 & 7.98 \\
& 8.0 & 1.07 & 1.1 & 0.36 & 0.8 & 503.6 & 0.35 & 93 & 3.70 & 1156.5 & 0.31 & 161 & 6.42 \\
\hline 600 & 1.0 & 0.24 & 2.2 & 0.05 & 2.1 & 26.0 & 1.84 & 278 & 11.10 & 62.1 & 1.79 & 600 & 23.98 \\
& $\mathbf{2 . 0}$ & $\mathbf{0 . 1 9}$ & $\mathbf{1 . 6}$ & $\mathbf{0 . 1 8}$ & $\mathbf{1 . 6}$ & $\mathbf{1 0 0 . 1}$ & $\mathbf{0 . 9 4}$ & $\mathbf{1 8 6}$ & $\mathbf{7 . 4 2}$ & $\mathbf{2 5 4 . 2}$ & $\mathbf{0 . 8 8}$ & $\mathbf{3 8 9}$ & $\mathbf{1 5 . 5 4}$ \\
& 3.0 & 0.19 & 1.4 & 0.23 & 1.6 & 182.5 & 0.70 & 137 & 5.46 & 478.0 & 0.64 & 284 & 11.34 \\
& 4.0 & 0.22 & 1.3 & 0.26 & 1.6 & 271.6 & 0.57 & 113 & 4.50 & 726.0 & 0.52 & 230 & 9.18 \\
& 5.0 & 0.26 & 1.3 & 0.29 & 1.6 & 368.7 & 0.49 & 97 & 3.86 & 1002.4 & 0.44 & 196 & 7.82 \\
& 6.0 & 0.31 & 1.2 & 0.31 & 1.6 & 475.2 & 0.43 & 85 & 3.38 & 1313.1 & 0.39 & 171 & 6.82 \\
& 8.0 & 0.46 & 1.2 & 0.36 & 1.6 & 722.1 & 0.35 & 69 & 2.74 & 2063.7 & 0.31 & 136 & 5.42 \\
\hline
\end{tabular}

The devices at the abutments are significantly shorter than those at the towers because the length of the damper is directly proportional to the yielding force, therefore: $L_{d, A}=L_{d, T} \cdot k_{T}$.

Finally, the optimal damper ductility $\left(\mu_{d, o p t}\right)$ is selected in Step 7 as the value that minimises the performance factor $F_{R d}$ defined in Eq. (12). In order to obtain $F_{R d}$, the admissible values of the structural response are set as follows: (1) the maximum admissible percentage of the input energy that is dissipated by inelastic excursions in the towers during the earthquake is considered $25 \%$ (i.e. $\Omega_{a d m}=0.25$ ) [21], and (2) the maximum admissible deck-tower relative displacement is set as $u_{d T, a d m}^{\max }=1.0 \mathrm{~m}$ in this work, which is the distance between the deck and the tower in the transverse direction in the proposed bridges (Fig. 2 (e)). The performance factor $F_{R d}$ included in Table III is calculated from the results of the dynamic analysis, as discussed in the next section. The values of $F_{R d}$ are obtained by considering the arithmetic mean plus one standard deviation $(s)$ of the results obtained from the set of 12 accelerograms. Large values of the design ductility $\left(\mu_{d}>5\right)$ are strongly penalised by $F_{R d}$ due to the risk of low-cycle fatigue (Section 6.4). In the range of low design ductilities $\left(\mu_{d}<2\right)$ the low-cycle fatigue risk is reduced, however, the response is usually not optimal in terms of energy dissipation (Section 6.1) and peak damper displacement (Section 6.3). As a result, the optimal damper ductility levels range between 2 and 5 in the three bridges.

\section{NONLINEAR RESPONSE HISTORY ANALYSIS AND DISCUSSION}

The seismic response of the bridges with the dampers shown in Table III is studied in this section by means of the Nonlinear Response History dynamic Analysis (NL-RHA) of the complete bridge FE models (including the deck, the cable-system and the towers) under the 12 records described in Section 4. For comparison purposes, the models with stiff and floating connections are also included in the discussion. The Hilber-Hughes-Taylor implicit algorithm [37] implemented in ABAQUS [32] is used for the numerical integration, with maximum and minimum admissible time-steps of $10^{-2}$ and $10^{-12} \mathrm{~s}$, respectively. The inherent structural damping ratio is $5 \%$ and it is defined by means of a Rayleigh damping distribution in the range of relevant vibration modes mentioned previously. 
The NL-RHA results were postprocessed to obtain the arithmetic mean and the standard deviation $(s)$ of the response parameters at the towers, the deck and the TADAS devices.

\subsection{Energy balance and damage ratio}

The evolution of the energy balance during the earthquake is especially important in bridges equipped with dampers because these are designed to minimise the energy dissipated by inelastic excursions in the main structure. Fig. 6 compares the energy introduced by the ground motion $\left(E_{W}\right)$ with the cumulative energy dissipated through material nonlinearity in the tower legs $\left(E_{S p \text {,legs }}\right)$ and the TADAS dampers ( $E_{S p, \mathrm{dA}}$ at the abutments and $E_{S p, \mathrm{dT}}$ at the towers). The case considered is the $200 \mathrm{~m}$ span bridge under Record \#4 (with the largest $S_{a}\left(T_{1}\right)$ ). A strong reduction of the energy dissipated by the tower legs is observed when the TADAS devices (with $\mu_{d}=\mu_{d, \text { opt }}=5$ ) are located at the supports of the deck. At the end of the simulation, $E_{S p \text {,legs }}$ in the $200 \mathrm{~m}$ bridge equipped with these dampers is only $24 \%$ of that in the model with stiff deck-tower connection. This represents an important improvement in the seismic response because the tower legs carry the loads from the deck directly to the foundation. The dampers, in turn, dissipate a considerable part of the input energy, especially the ones located at the deck-tower connections. This is due to the larger proportion of the mass of the deck that corresponds to these dampers $\left(M_{T}>M_{A}\right.$ in Eq. (3)). The results in Fig. 6 also show that the dampers at the abutments $\left(E_{S p, \mathrm{dA}}\right)$ and at the towers $\left(E_{S p, \mathrm{dT}}\right)$ start yielding at the same instant $(t=5.2 \mathrm{~s}$ for Record \#4). This type of response indicates that the yielding force of the dampers along the deck is adequately distributed by using Eq. (2).

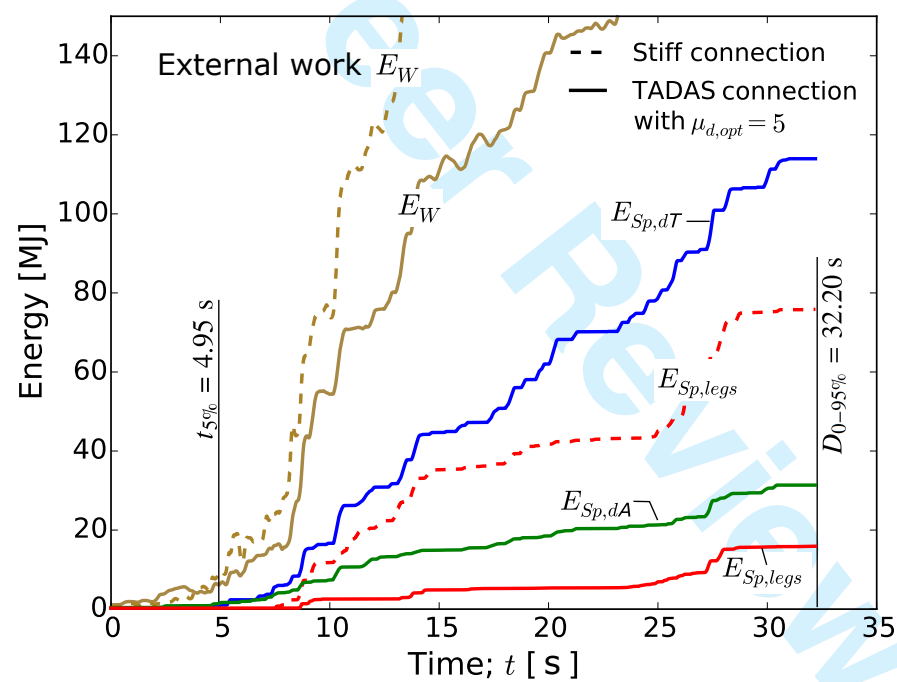

Figure 6. Evolution of the energy input by the earthquake $\left(E_{W}\right)$ and the cumulative plastic energy dissipated by the tower legs $\left(E_{S p, \text { legs }}\right)$ in the $200 \mathrm{~m}$ span bridge with stiff and TADAS connections. The energy dissipated by the dampers at the abutments $\left(E_{S p, \mathrm{dA}}\right)$ and at the towers $\left(E_{S p, \mathrm{dT}}\right)$ is included. Record \#4.

A ratio between the total energy that is dissipated by plastic deformations in the structural components and the energy introduced by the earthquake is defined in order to compare the results of different bridges [38]. The response parameter proposed in this work, referred to as damage ratio $\Omega$, distinguishes the damage in different parts of the tower $\left(E_{S p, j}\right)$ and is defined as:

$$
\Omega=\sum_{j} \Omega_{j}=\sum_{j} \frac{E_{S p, j}}{E_{W}}=\frac{\sum_{j} \int_{0}^{D_{0,95 \%}}\left(\int_{V_{j}} \sigma^{c}: \dot{\boldsymbol{\varepsilon}}^{p l} \mathrm{~d} V\right) \mathrm{d} \tau}{\int_{0}^{D_{0,95 \%}}\left(\int_{V_{\text {tot }}}\left(-\mathbf{m} \iota \ddot{\mathbf{u}}_{g}\right) \cdot \mathbf{v} \mathrm{d} V\right) \mathrm{d} \tau}
$$


where $\Omega_{j}$ is the damage ratio in the $j$-th structural member, with $j=\mathrm{s} 1$, s2, s3 and "legs" representing the contribution to the total energy dissipation of the lower, medium, upper struts and the two lateral legs of the tower, respectively, as shown in Fig. 2(b). $\int_{V}(\cdot)$ represents the integral over the volume $V$ of the portion of the structure that is under study. In the calculation of the input energy $\left(E_{W}\right)$, the whole bridge model is considered, hence $V=V_{t o t}$. However, in the calculation of the plastic dissipation at different structural members only the volume $V_{j}$ corresponding to the $j$-th member is considered (taking into account that each member is repeated in the two towers of the bridge). $\sigma^{c}$ is the stress derived from the constitutive equations, without viscous dissipation effects; $\dot{\boldsymbol{\varepsilon}}^{p l}$ is the plastic strain rate; $D_{0,95 \%}$ is the reduced duration of the earthquake (as discussed in Section 4); $\mathbf{m}$ is the mass matrix of the structure; $\boldsymbol{\iota}$ is the influence matrix that connects the degrees of freedom of the structure with the directions in which the accelerograms are applied: $\ddot{\mathbf{u}}_{g}^{T}(t)=\left(\ddot{u}_{g}^{X}, \ddot{u}_{g}^{Y}, \ddot{u}_{g}^{Z}\right)$, that reduces to $\ddot{u}_{g}^{Y}$ in this study. Note that the energy dissipated by the dampers is not included in $\Omega$ in order to quantify the fraction of the input seismic energy that is dissipated by the main structure. Ideally, the dampers should absorb all the energy that would be otherwise dissipated by inelastic excursions in the structure, in which case $\Omega=0$.

Fig. 7 presents the damage ratio $\Omega_{j}$ for all the damper ductility values considered in the study. The solutions with stiff and floating connections are also included for comparison purposes. The different parts in each bar represent the contribution (arithmetic mean) of each component of the tower $\left(\Omega_{j}\right)$ to the total value of $\Omega$. The first important remark from Fig. 7 is the significant dissipation by inelastic excursions that take place in the towers when the deck-tower connection is fully rigid. This is especially important for the shortest bridge, in which $32 \%$ of the total energy of the earthquake translates into tower damage. Furthermore, $12 \%$ of the input energy is dissipated by plastic deformations in the tower legs $\left(\Omega_{\text {legs }}=0.12\right)$, which could compromise the integrity of the whole structure. In the same bridge $\left(L_{P}=200 \mathrm{~m}\right)$, the floating deck-tower connection reduces the dissipation in the tower legs down to approximately $1 \%$. Analogous damage levels in the tower legs are also achieved with the TADAS connection but, in addition: (1) the lower transverse strut of the towers (s1) is better protected (see the negligible $\Omega_{s 1}$ with the TADAS devices), and (2) the deformability of the deck under lateral service loads is controlled by the stiffness of the damper.

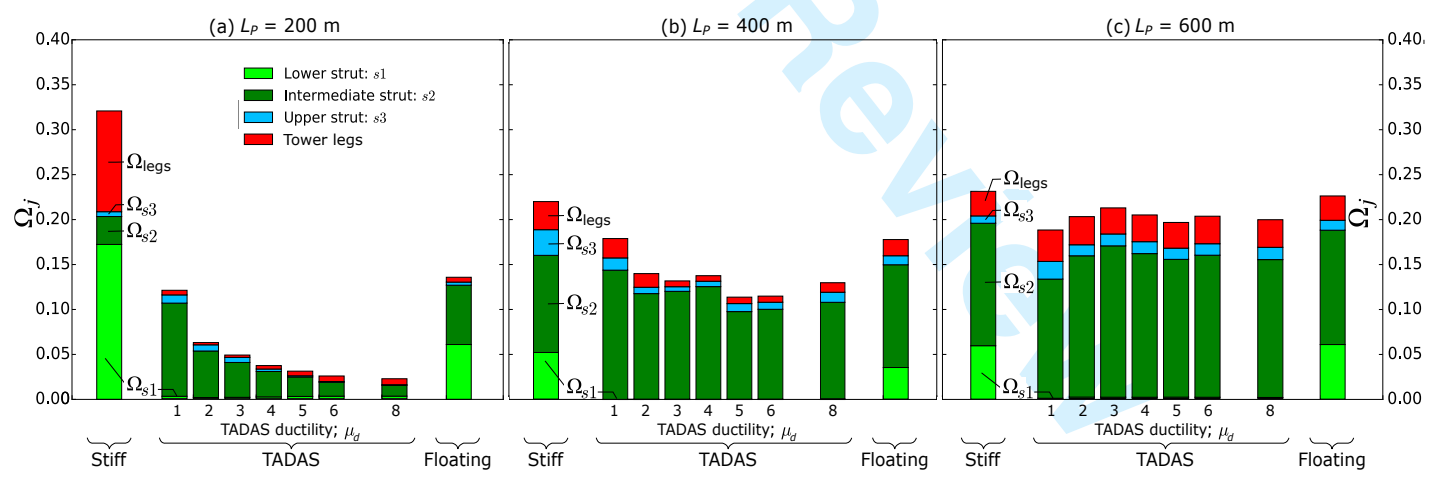

Figure 7. Damage ratio $\Omega_{j}$ in bridges with (a) $200 \mathrm{~m}$, (b) $400 \mathrm{~m}$ and (c) $600 \mathrm{~m}$ main span.

Fig. 7 also compares the results for different damper ductilities $\left(\mu_{d}\right)$ in the three bridges. For all the design ductility levels the TADAS devices reduce significantly the damage of the towers in the $200 \mathrm{~m}$ span bridge (Fig. 7(a)). It is observed that the towers of this particular bridge are increasingly better protected at larger $\mu_{d}$. A maximum reduction of the total tower damage from $\Omega=0.32$ to 0.02 (i.e. 94\%) is achieved by substituting the stiff deck-tower connection with the TADAS dampers with $\mu_{d}=8$ in the model with $L_{P}=200 \mathrm{~m}$. Likewise, the TADAS connection with $\mu_{d}=5$ reduces the tower damage by $91 \%$. In fact, the influence of the ductility of the TADAS devices on the energy dissipated by plastic deformations in the towers is small for $\mu_{d}>5$, in all the bridges.

A more modest reduction of damage with the TADAS connection is observed in the towers of the 400 and (especially) $600 \mathrm{~m}$ main span bridges in Fig. 7. Some configurations of the TADAS dampers lead to total tower damage levels that are similar to those with the stiff connection in these 


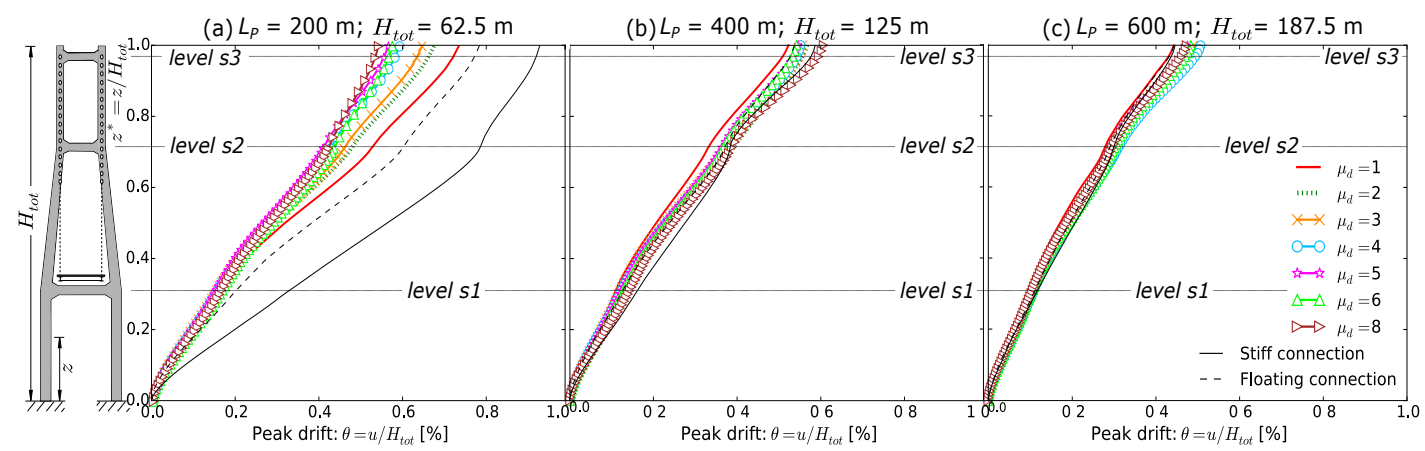

Figure 8. Peak lateral drift (mean) along the tower legs: (a) $200 \mathrm{~m}$, (b) $400 \mathrm{~m}$ and (c) $600 \mathrm{~m}$ span bridges. 


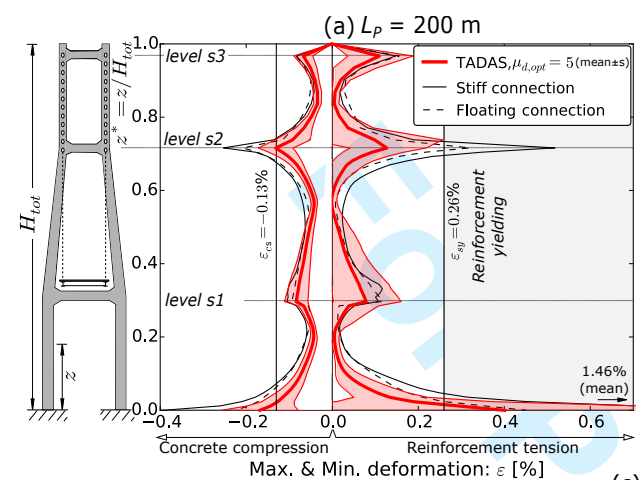

Fig. 9 presents the peak normal deformation that is recorded during the earthquake along the legs of the towers in the bridges without dampers and with the optimal TADAS devices. The results include the effect of the self-weight of the structure. The compressive deformation (negative) is measured in the corners of the sections, whilst the tensile deformation (positive) refers to the outer perimeter of longitudinal reinforcement. The different dimensions of the sections and the position of the reinforcement along the tower are considered according to the arrangement presented in Fig. 2(b). The peak deformations in tension and compression shown in Fig. 9 are not concomitant and can be directly compared with the tensile and compressive elastic limits and strength of the materials. The curves refer to the arithmetic mean of the results obtained with the set of 12 records. The coloured bands centred on the mean response represent one standard deviation $(s)$.

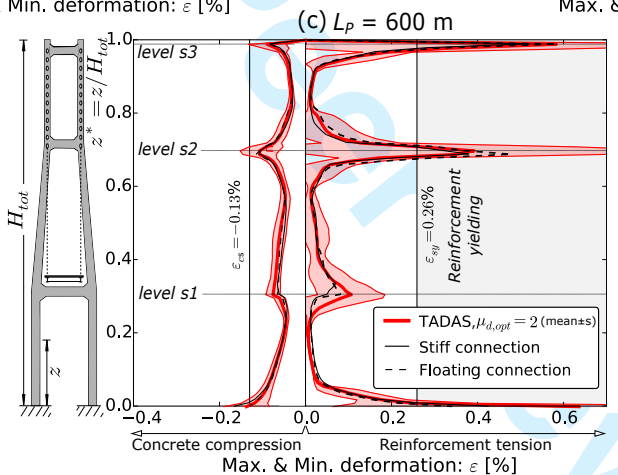

Figure 9. Peak normal deformation along the tower legs for the models with the optimal TADAS devices, and without them, in bridges with (a) $200 \mathrm{~m}$, (b) $400 \mathrm{~m}$ and (c) $600 \mathrm{~m}$ main span.

All the structures show a significant localisation of the inelastic demand at the strut-leg connections of the towers and at their base. From the design point of view, this limits the number of critical sections that require high quantities of reinforcement. The beneficial effect of the TADAS dampers is clear in the $200 \mathrm{~m}$ span bridge (Fig. 9(a)), in which the concrete remains virtually elastic in compression and the reinforcement yielding is largely prevented along the tower. The peak tensile deformation (arithmetic mean) in the reinforcement at the tower base of the $200 \mathrm{~m}$ bridge is reduced from $\varepsilon_{s}=1.46 \%$ with the stiff connection, and $\varepsilon_{s}=0.44 \%$ with the floating connection, to $\varepsilon_{s}=0.40 \%$ with the optimal TADAS configuration. Record \#4 is largely responsible for the moderate yielding of the reinforcement steel $\left(\varepsilon_{s y}=0.26 \%\right)$ at the tower base in the model with the TADAS connection. In terms of deformations, the improvement in the seismic response of the 200 $\mathrm{m}$ bridge tower legs with the TADAS devices is more evident above the deck, and especially at the level of the connection with the intermediate strut (s2). At this position, the demand of deformation is reduced respectively by $76 \%$ and $54 \%$ in tension and compression when comparing with the stiff connection. In the $400 \mathrm{~m}$ span bridge with optimal TADAS devices the deformation of the towers above the deck is significantly reduced (Fig. 9(b)), although the reinforcement yields at the connections of the legs with the transverse struts s2 and s3. At the tower base, the tensile deformation is reduced by $29 \%$ with the optimal TADAS dampers, which is below the reduction achieved in the 


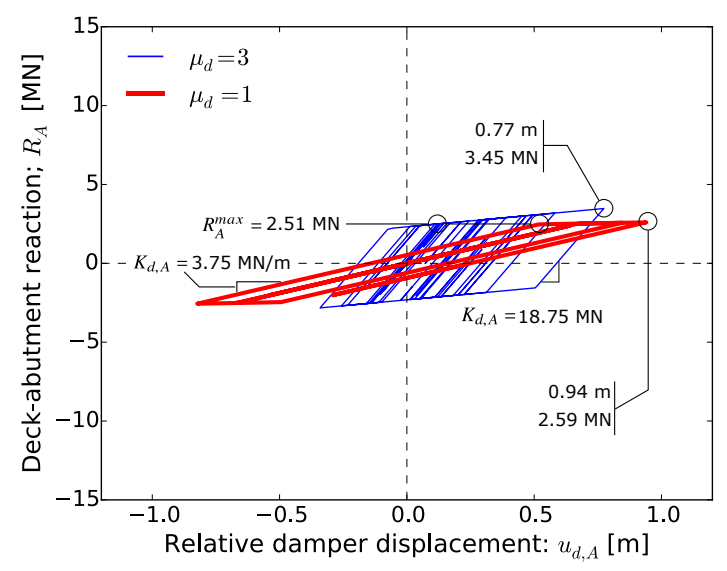

(a)

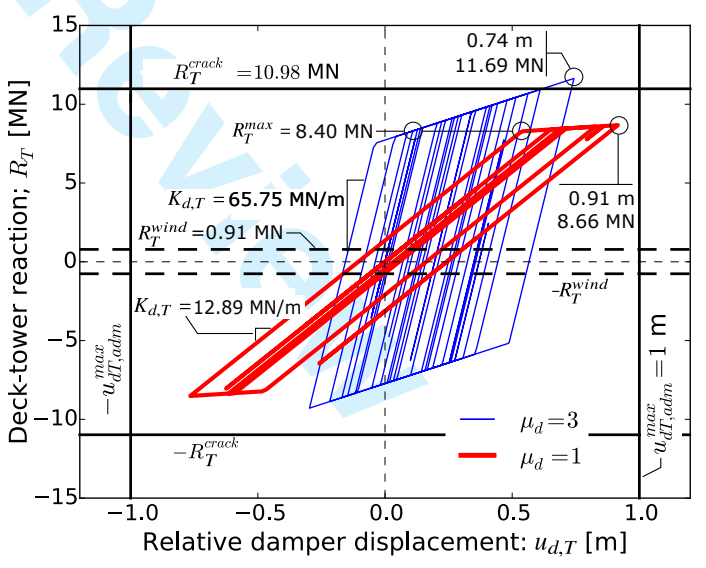

(b)

Figure 10. Load-displacement response of the TADAS devices with different design ductilities in the $200 \mathrm{~m}$ bridge subject to Record \#4; (a) dampers at the abutments, (b) dampers at the towers. The admissible limits are included in the damper at the towers, as well as the force induced by the design wind action $\left(R_{T}^{\text {wind }}\right)$.

$200 \mathrm{~m}$ bridge and it does not prevent yielding at this section. However, it should be noted that the damage in the towers of the structures with conventional main span lengths of 200 and $400 \mathrm{~m}$ is moderate and they remain essentially elastic thanks to the hysteretic response of the dampers under extreme seismic actions (especially the shortest bridge). This satisfies the design criterion in existing cable-supported bridges with MD located in seismic areas with design ground motions of similar intensity (i.e. the SFOB bridge [6]).

Fig. 9(c) shows the peak deformations in the towers of the largest bridge. The response at the anchorage zone of the $600 \mathrm{~m}$ bridge is almost insensitive to the deck-tower connection (where the dampers are located) because of the large distance between both. The demand of deformation at the tower base is increased by $34 \%$ when the TADAS devices are equipped in the $600 \mathrm{~m}$ bridge, in comparison with the response with stiff connection. Fig. 9(c) shows the severe cracking and the yielding of the reinforcement in the sections at the anchorage area near the strut-leg connections, which is related to the large damage in the intermediate strut $\left(\Omega_{s 2}\right)$ of the $600 \mathrm{~m}$ bridge towers observed in Fig. 7(c). However, the ultimate deformation of the concrete and the steel in the towers is not exceeded in any of the records, for none of the design solutions and main spans considered.

\subsection{Load-displacement response of the dampers}

Fig. 10 shows the load-displacement response of the TADAS dampers in the $200 \mathrm{~m}$ bridge subject to the ground motion Record \#4, for two different ductility levels. This figure illustrates the lower tiffness and yielding force of the devices at the abutments $\left(K_{d, A}\right.$ and $\left.R_{A}^{\max }\right)$ in comparison with hose at the towers (Table III). It is also observed that the area enclosed by the load-displacement ve of the dampers at the towers is significantly larger than that at the abutments, which is directly the the $85 \%$ increment in the energy dissipated at the deck-tower connections $\left(E_{S p, d T}\right)$ when mpared to the one dissipated at the deck-abutment connections $\left(E_{S p, d A}\right)$ in Fig. 6 . The dampers ined to behave elastically $\left(\mu_{d}=1\right)$ dissipate some energy under the accelerograms in which sectral acceleration at the fundamental period is larger than the target spectrum for which the dampers are designed, e.g. Record \#4 in Fig. 4. However, it should be recalled that in all cases the average ductility demand, considering the complete set of records, is close to the target one.

The dampers yield before exerting the maximum admissible force into the towers: $R_{T}^{\max }=8.4$ $\mathrm{MN}<R_{T}^{\text {crack }}=10.98 \mathrm{MN}$, as shown in Fig. 10(b). However, due to the post-yielding hardening of the damper, the maximum deck-tower reaction slightly exceeds the admissible limit $\left(R_{T}^{\text {crack }}\right)$ for Record \#4. This is considered acceptable because it is only observed under the strongest record of the set, with the average value of the peak deck-tower reaction below the maximum admissible 
level. Fig. 10(b) shows an increment of strength of 39\% in the tower damper when its displacement is 6 times larger than the elastic limit, which is consistent with experimental testing [22].

In a separate static analysis, the design wind action (30 m/s basic wind speed [39]) is applied as a uniform lateral pressure along the entire length of the deck to obtain a conservative value of the service load resisted by the TADAS devices at the towers $\left(R_{T}^{\text {wind }}\right)$ and at the abutments. From the study of the 200, 400 and $600 \mathrm{~m}$ span bridges the wind forces are $R_{T}^{\text {wind }}=0.91,2.42$ and $4.45 \mathrm{MN}$, respectively, which fall below the yielding loads of the dampers at the towers $\left(R_{T}^{\max }=8.4,22.4\right.$ and 39.0 MN, respectively). The same is observed in the dampers at the abutments. Consequently, the design wind action is not able to activate the dissipation of the TADAS devices, which reduces the risk of fatigue and permanent displacement of the deck under wind loads or moderate earthquakes. It is also verified, for the particular case presented in Fig. 10, that the maximum relative displacement between the deck and the towers during the earthquake $\left(u_{d T}^{\max }\right)$ is smaller than the available space between the girder edges and the tower legs $\left(u_{d T, a d m}^{\max }=1 \mathrm{~m}\right)$.

In order to give a broader view of the response, Fig. 11 shows the arithmetic mean of the peak damper displacement demand $\left(u_{d, i}^{\max }\right.$, where $i=A$ for the abutments and $T$ for the towers) in the three bridges, considering the complete set of ground motions. The standard deviation of the results (coloured band $s$ ) is only given for the tower dampers to improve clarity but similar values are obtained at the abutments. By increasing the ductility of the damper, the demand of displacement at the deck connections is reduced, at higher rate for low ductility levels. This can be explained by the larger elastic stiffness that is required from the damper in order to achieve a higher ductility demand with the same target displacement and yielding load, which results in lower vibration periods (see Table III) and spectral displacements (Fig. 4(b)). For the same reason, the bridges with long spans $(400$ and $600 \mathrm{~m}$ ) present smaller displacement demands in the dampers and the utilisation of these devices is reduced. The damper displacement demand at the towers decreases from 0.28 to only 0.05 $\mathrm{m}$ (approximately $80 \%$ ) by increasing the main span from 200 to $600 \mathrm{~m}$, for $\mu_{d}=8$. Accounting for one standard deviation $(s)$, the peak deck-tower displacement is well below the $1 \mathrm{~m}$ transverse space between the edges of the deck and the legs of the towers in all cases, which prevents lateral impacts between both elements during the earthquake.

The peak relative displacement between the deck and the towers in the uncontrolled bridges (with stiff and floating connections) and the bridges equipped with the TADAS devices is also compared in Fig. 11. All the solutions for the deck-tower connection satisfy the maximum displacement requirements. However, if the deck is disconnected from the towers in the transverse direction (floating solution) the response under lateral service loads (e.g. wind actions) is too flexible. For this reason, certain transverse stiffness is required at the deck-tower connection and this can be directly provided by the elastic stiffness of the TADAS devices $\left(K_{d, i}\right)$. Furthermore, the optimal TADAS connection presents peak displacements that are smaller than those resulting from the floating connection, especially for the $400 \mathrm{~m}$ span bridge in which the reduction is down to $66 \%$.

The mean relative displacement demand in the dampers at the abutments is close to the target displacement $\left(S_{d}\right)$ resulting from the design Step 4. However, the relative displacement of the dampers at the towers is lower than the one at the abutments. This is partly because Fig. 11 refers to the peak relative displacement of the TADAS devices, measured between the top and the bottom of the triangular plates, and it does not account for the transverse movement of the towers when these dampers yield: $u_{s, T}^{y}=0.023,0.031$ and $0.046 \mathrm{~m}$ for the $200,400,600 \mathrm{~m}$ span bridges, respectively. However, the lateral displacement of the tower in the $600 \mathrm{~m}$ span bridge cannot entirely explain the difference between the displacement of the dampers along the deck (up to $0.45 \mathrm{~m}$ ). Fig. 12 presents the transverse displacement of the deck (plan view) in the bridges with the TADAS dampers $\left(\mu_{d}=5\right)$ subject to Record \#4. It is apparent that the $200 \mathrm{~m}$ bridge is dominated by the uniform lateral motion of the deck when the dampers yield, which is consistent with the SDOF motion idealisation proposed in the design method (Fig. 1(b)). Fig. 12 also shows that the displacement demand in the dampers along the deck is similar in the small bridge. As the main span increases the contribution of high-order vibration modes to the lateral response is more pronounced. This is partially accounted for in the distribution of the capacity of the dampers and the vibrating mass in the proposed method (Eqs. (2) and (3)), resulting in the simultaneous yielding of the devices. 
However, after yielding, the lateral movement of the deck is clearly not uniform in the $600 \mathrm{~m}$ bridge (Fig. 12(c)), leading to a significant difference in the displacement demands between the dampers at the abutments and the towers (Fig. 11(c)). Nevertheless, the results of the simulations indicate that this difference is accommodated in the deck without exceeding the elastic limits of the materials due to its large transverse flexibility and length.

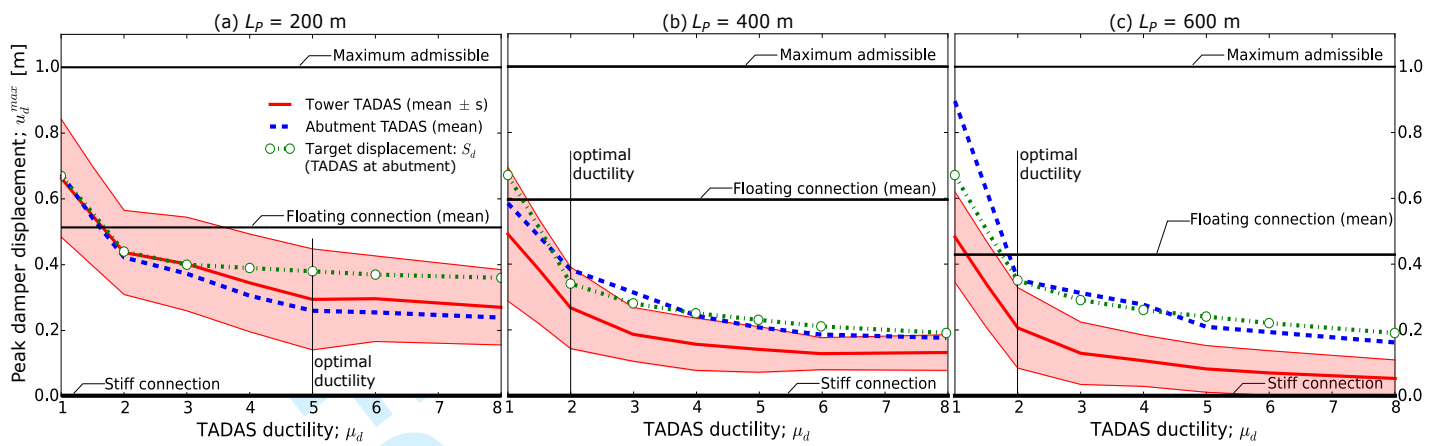

Figure 11. Peak relative deck-support displacement: (a) $200 \mathrm{~m}$, (b) $400 \mathrm{~m}$ and (c) $600 \mathrm{~m}$ span bridges.

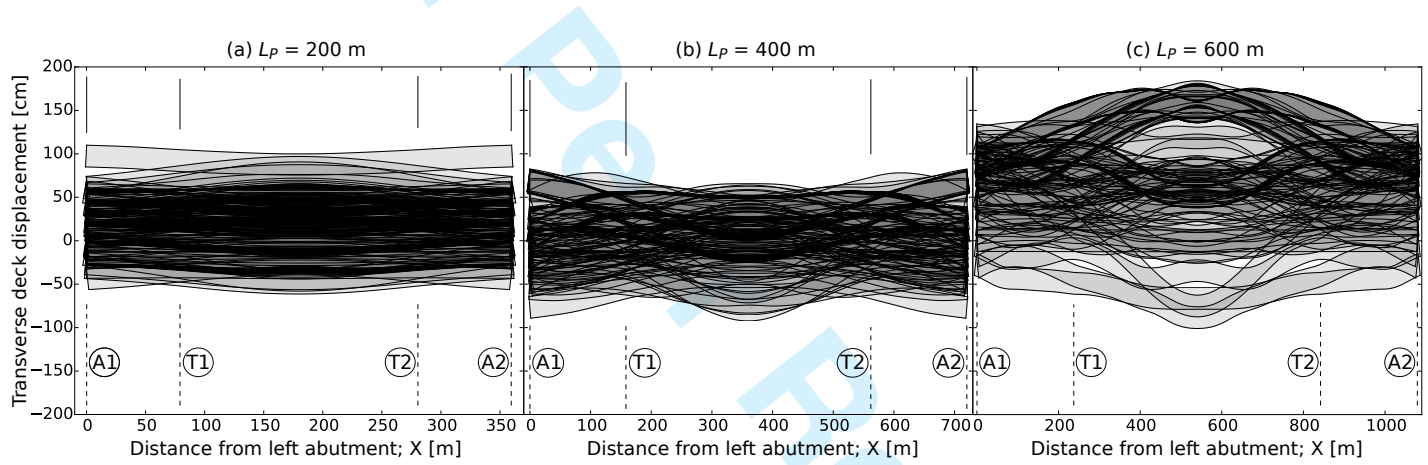

Figure 12. Plan view of the deck in different time-steps during the seismic response: (a) $200 \mathrm{~m}$, (b) $400 \mathrm{~m}$ and (c) $600 \mathrm{~m}$ span bridges with the TADAS dampers $\left(\mu_{d}=5\right)$. Record \#4.

\subsection{Low-cycle fatigue risk in the dampers}

The large inelastic excursions in the dampers during the earthquake (see Fig. 10) make these devices sensitive to low-cycle fatigue. In this work, a simplified approach based on the number of cycles to failure given by the Coffin-Manson rule $\left(N_{f}\right)$ in a steel specimen subject to a constant plastic strain amplitude $\Delta \varepsilon^{p} / 2$ [24] is adopted:

$$
N_{f}=\frac{1}{2}\left(\frac{\Delta \varepsilon^{p}}{2 \varepsilon_{f}^{\prime}}\right)^{1 / c}
$$

where $\varepsilon_{f}^{\prime}$ is the failure strain for a single reversal (referred to as fatigue ductility coefficient) and it is considered equal to the ultimate plastic strain of the material in a monotonic test, i.e. $\varepsilon_{f}^{\prime}=\varepsilon_{s u}^{p}=11.1 \% ; c$ is the fatigue ductility exponent, which depends on the type of steel employed in the plates of the dampers, in this study $c=-0.55$.

The displacement time-histories of the dampers that result from the FE model of the bridge in NL-RHA $\left(u_{d, i}(t)\right.$ in Fig. 10) need to be transformed into strain along the triangular plates $\left(\varepsilon_{i}(t)\right)$ in order to obtain the number of cycles to failure $\left(N_{f}\right)$ from Eq. (14). The distribution of strain in the plates is uniform due to their triangular shape and it is related to the displacement at the top of the plate through its thickness $\left(t_{p}\right)$ and height $\left(H_{p, i}\right)$ : 


$$
\varepsilon_{i}(t)=u_{d, i}(t) \frac{t_{p}}{H_{p, i}^{2}}
$$

The Palmgren-Miner index is employed to account for the non-constant plastic strain amplitude in the TADAS damper at the $i$-th support during the earthquake:

$$
\mathrm{PM}_{i}=\sum_{m}^{N_{c}} \frac{1}{\left.N_{f}\right|_{m}}
$$

$\mathrm{PM}_{i}$ represents the low-cycle fatigue failure risk $\left(\mathrm{PM}_{i} \geq 1\right.$ means failure) in the TADAS device at the $i$-th support, with $i=A, T$ for the abutments and the towers, respectively; $N_{c}$ is the number of cycles with plasticity at the dampers; $\left.N_{f}\right|_{m}$ is the number of cycles to failure obtained from Eq. (14) if the plastic strain range amplitude of the $m$-th cycle $\left(\Delta \varepsilon_{m}^{p} / 2\right)$ is kept constant.

The results of $\mathrm{PM}_{i}$ for all the records and the complete range of damper design ductilities are included in Fig. 13, along with the arithmetic mean and one standard deviation. The low-cycle fatigue risk strongly increases with the design ductility of the damper, and it is more pronounced in the TADAS devices located at the abutments than those at the towers. This is attributed to the lateral flexibility of the towers, which reduces the relative displacement of the dampers at these locations. The mean value of $\mathrm{PM}_{i}$ plus one standard deviation is below failure in all cases, but the dampers with large design ductilities fail due to the low-cycle fatigue under the strongest record of the set (Record \#4), particularly in the 400 and $600 \mathrm{~m}$ span bridges. However, the selected TADAS devices with optimal ductilities $\left(\mu_{d, o p t}\right)$ do not fail for any of the records.

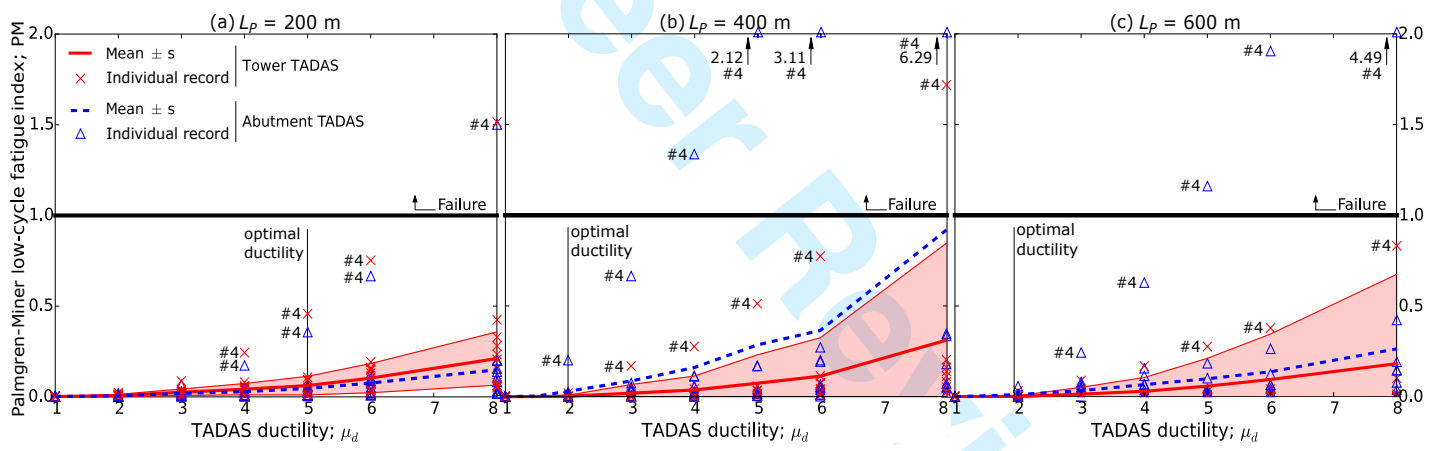

Figure 13. Low-cycle fatigue (Palmgren-Miner) index: (a) $200 \mathrm{~m}$, (b) $400 \mathrm{~m}$ and (c) $600 \mathrm{~m}$ span bridges.

\section{CONCLUSIONS}

In this paper, a new method is proposed to design optimal yielding metallic dampers for the seismic control of short-to-medium span cable-stayed bridges in the transverse direction. Although this study has focused on Triangular-plate Added Damping And Stiffness (TADAS) devices, the method is applicable to a wide range of metallic dampers connecting the deck to the supports. The methodology assumes that the lateral response of the deck can be described by an equivalent SDOF system of uniform motion. The governing design parameter is the ductility of the TADAS dampers, which defines in turn the dimensions of the plates. A multi-objective response factor that accounts for the energy dissipation by plastic deformation in the structure, the peak displacement in the deck-tower connection and the low-cycle fatigue risk in the dampers is proposed to find the optimal damper ductility.

The characteristic seismic response of cable-stayed bridges has been explicitly considered in the following aspects of the proposed methodology: (1) the TADAS devices at the deck-tower connections are set to yield before cracking in the tower is initiated in order to prevent the degradation of the tower stiffness after cracking that is observed in the nonlinear static analysis; 
(2) the yielding force of the dampers at the abutments is obtained as a fraction $\left(k_{R}\right)$ of the capacity in the tower dampers in order to enforce the lateral 'rigid body' motion of the deck and to obtain a synchronous response of the dampers along its length during the earthquake; and (3) the vibrating mass in the design procedure accounts for the part of the deck that, due to its large transverse flexibility, moves without affecting the TADAS devices at the towers.

The nonlinear static and dynamic transverse seismic responses of three cable-stayed bridges with 200, 400 and $600 \mathrm{~m}$ main span lengths and different deck-support connections have been explored. Series of deterministic nonlinear dynamic analysis under the extreme design earthquake were run based on expected material properties. It was observed that the design of the TADAS devices is governed by the damage in the towers and the damper displacement for low ductility levels (below $\mu_{d}=2$ ), and by the low-cycle fatigue risk for large ductility levels (above $\mu_{d}=5$ ). The optimal design ductility of the dampers falls between these two values and the resulting TADAS connection can reduce the seismic energy dissipated by plastic deformation in the towers, especially along the legs, which have a paramount importance for the integrity of the whole structure. This is of particular significance in the $200 \mathrm{~m}$ bridge, in which the optimal TADAS dampers reduce the damage and the peak lateral drift in the towers by $91 \%$ and $58 \%$, respectively, preventing significant cracking in these members in comparison with the conventional solution with fully-rigid transverse decktower connection. The benefits of the dampers in the $400 \mathrm{~m}$ span bridge are only appreciable for the optimal TADAS devices $(50 \%$ and $3 \%$ reduction in the tower damage and peak displacement, respectively) which highlights the importance of including the target ductility of the damper in the design procedure. This response meets the performance requirements in existing cable-supported bridges designed to resist earthquakes with similar intensities. However, the beneficial effect of the TADAS dampers at the transverse deck connections in the $400 \mathrm{~m}$ span bridge is moderate in comparison with the shortest bridge, while it is completely negligible in the $600 \mathrm{~m}$ span bridge. This is due to the relatively smaller influence of the deck-tower connection on the transverse seismic response of the towers in longer bridges. This result suggests further research on supplemental damping systems for the control of the transverse seismic behaviour of large cable-stayed bridge towers, in which the dampers should be distributed along the height of the tower and not only at the deck-tower connections.

The validity of the proposed design method for TADAS devices has been proved in conventional short-to-medium span bridges under the extreme ground shaking. However, the assumed uniform motion of the deck ignores the contribution of high-order modes that are particularly relevant for the $600 \mathrm{~m}$ span bridge. The applicability of the design framework can be extended to long-span bridges by defining an equivalent SDOF system that accounts for the contribution of high-order vibration modes. It should be also noted that further reliability studies are needed to establish appropriate safety factors for design purposes, accounting for the uncertainties on the response of the dampers and their mechanical properties. These should be addressed by means of extensive experimental testing and detailed FE analysis of the optimal TADAS dampers resulting from the proposed design.

\section{REFERENCES}

1. Huang Y, Bertero V, Wada A. Innovative strategies in earthquake engineering. Earthquake Engineering: From Engineering Seismology to Performance-Based Engineering, CRC Press, 2004.

2. Kawashima K, Unjoh S, Tsunomono M. Estimation of damping ratio of cable - stayed bridges for seismic design. Journal of Structural Engineering 1993; 119(4):1015-1031.

3. Combault J, Pecker A, Teyssandier J, Tourtois J. Rion-antirion bridge, greece - concept, design and construction. Structural Engineering International 2005; 1:22 - 27.

4. Pappin J, Kite S. Seismic design of stonecutters bridge, hong kong. $14^{\text {th }}$ World Conference on Earthquake Engineering, Beijing (China), 2008.

5. McDaniel C, Uang C, Seible F. Cyclic testing of built-up steel shear links for the new bay bridge. Journal of Structural Engineering 2003; 129(6):801-809.

6. McDaniel C, Seible F. Influence of inelastic tower links on cable-supported bridge response. Journal of Bridge Engineering 2005; 10(3):272-280.

7. Xing S, Camara A, Ye A. Effects of seismic devices on transverse responses of piers in the sutong bridge. Earthquake Engineering and Engineering Vibration 2015; 14(4):611-623.

8. Infanti S, Papanikolas P, Benzoni G, Castellano M. Rion antirion bridge; design and full - scale testing of the seismic protection devices. Proceedings of $13^{\text {th }}$ World Conference on Earthquake Engineering, Vancouver B.C. 
(Canada), 2004. Paper No. 2174.

9. Celebi M. Real-time seismic monitoring of the new cape girardeau bridge and preliminary analyses of recorded data: an overview. Earthquake Spectra 2006; 22(3):609-630.

10. Enomoto M, Takano H, Ogasawara M, Takahashi W, Watanabe N, Inoue M. Design and study of the tsurumi fairway bridge. Cable-stayed and Suspension Bridges; IABSE / FIP International Conference, vol. I, Deauville (France), 1994; 429-435.

11. Siringoringo D, Fujino Y, Namikawa K. Seismic response analyses of the yokohama bay cable-stayed bridge in the 2011 great east japan earthquake. Journal of Bridge Engineering 2014; 19(8):A4014 006

12. Ali H, Ghaffar A. Seismic passive control of cable-stayed bridges. Journal of Shock and Vibration 1995; 2(4):259272.

13. Ali H, Ghaffar A. Seismic energy dissipation for cable-stayed bridges using passive devices. Earthquake engineering and structural dynamics 1994; 23:877-893.

14. Soneji B, Jangid R. Passive hybrid systems for earthquake protection of cable-stayed bridges. Engineering Structures 2007; 29(1):57-70.

15. El-Bahey S, Bruneau M. Bridge piers with structural fuses and bi-steel columns. i: Experimental testing. Journal of Bridge Engineering 2012; 17(1):25-35.

16. El-Bahey S, Bruneau M. Bridge piers with structural fuses and bi-steel columns. ii: Analytical investigation. Journal of Bridge Engineering 2012; 17(1):36-46.

17. Berman J, Bruneau M. Development of self-stabilizing links for eccentrically braced frames. Proceedings of $14^{\text {th }}$ World Conference on Earthquake Engineering, Beijing (China), 2008.

18. Chang K, Mo Y, Chen C, Lai L, Chou C. Lessons learned from the damaged chi-lu cable-stayed bridge. Journal of Structural Engineering 2004; 9(4):343-352.

19. Gimsing N, Georgakis C. Cable supported bridges: Concept and design. John Wiley \& Sons (USA), 2011. 3rd Edition.

20. Calvi G, Sullivan T, Villani A. Conceptual seismic design of cable-stayed bridges. Journal of Earthquake Engineering 2010; 18(ISS8):1139-1171.

21. Camara A, Astiz M. Analysis and control of cable-stayed bridges subject to seismic action. Structural Engineering International 2014; 24(1):27-36.

22. Tsai K, Chen H, Hong C, Su Y. Design of steel triangular plate energy absorbers for seismic-resistant construction. Earthquake Spectra 1993; 9(3):505-528.

23. Priestley M, Seible F, Calvi G. Seismic design and retrofit of bridges. John Wiley and Sons, 1996.

24. Soong T, Dargush G. Passive energy dissipation systems in structural engineering. John Wiley and Sons: Chichester (UK), 1997.

25. Camara A, Efthymiou E. Deck-tower interaction in the transverse seismic response of cable-stayed bridges and optimum configurations. Engineering Structures 2016; 124:494-506.

26. Dwairi H, Kowalsky M, Nau J. Equivalent damping in support of direct displacement-based design. Journal of Earthquake Engineering 2007; 11(4):512-530.

27. Camara A, Astiz M, Ye A. Fundamental mode estimation for modern cable-stayed bridges considering the tower flexibility. Journal of Bridge Engineering 2014; 19:04014 015-1/12.

28. Taylor A, Rowe R, JE B. Design and behavior of thin walls in hollow concrete bridge piers. Technical Report, Center for Transportation Research, The University of Texas at Austin November 1990. Report No. FHWA/TX$91+1180-1 \mathrm{~F}$

29. AASHTO. Standard specifications for highway bridges 2002. 17th Edition.

30. Mazars J, Pijaudier-Cabot G. Continuum damage theory - application to concrete. Journal of Engineering Mechanics 1989; 115(2):345-365.

31. Légeron F, Paultre P, Mazars J. Damage mechanics modelling of nonlinear seismic behavior of concrete structures. Journal of Structural Engineering June 2005; 131(6):946-955.

32. ABAQUS. Commercial Finite Element Software. Version 6.14. Providence (USA) 2014

33. Whittaker A, Bertero V, Thompson C, Javier Alonso L. Seismic testing of steel plate energy dissipation devices. Earthquake Spectra 1991; 7(4):563-604.

34. Ancheta T, Darragh R, Stewart J, Seyhan E, Silva W, Chiou B, Wooddell K, Graves R, Kottke A, Boore D, et al. Peer nga-west 2 database. Technical Report, Pacific Earthquake Engineering Research Center May 2013.

35. EN 1998-1: Design of structures for earthquake resistance. Part 1: General rules, seismic actions and rules for buildings 2004.

36. Hancock J, Bommer J, Stafford P. Number of scaled and matched accelerograms required for inelastic dynamic analysis. Earthquake engineering and structural dynamics 2008; 37:1585-1607.

37. Hilber H, Hughes T, Taylor R. Improved numerical dissipation of time integration algorithms in structural dynamics. Earthquake engineering and structural dynamics 1977; 5:283-292.

38. Camara A, Ruiz-Teran A, Stafford P. Structural behaviour and design criteria of under-deck cable-stayed bridges subjected to seismic action. Earthquake Engineering and Structural Dynamics 2012; 42(6):891-912.

39. EN 1991-1-4: Actions on structures - Part 1-4: General actions - Wind actions 2005. 